\title{
Recapitulation of Human Pathophysiology and Identification of Forensic Biomarkers in a Translational Swine Model of Chlorine Inhalation Injury
}

Satyanarayana Achanta ${ }^{1 *}$; Michael A. Gentile ${ }^{1}$; Carolyn J. Albert ${ }^{2}$; Kevin A. Schulte ${ }^{2}$; Brooke G. Pantazides $^{3}$, Brian S. Crow ${ }^{3}$, Jennifer Quiñones-González ${ }^{3, a}$, Jonas W. Perez ${ }^{3}$, David A. Ford ${ }^{2}$; Rakesh P. Patel ${ }^{4}$; Thomas A. Blake ${ }^{3}$, Michael D. Gunn ${ }^{5}$ and Sven E. Jordt ${ }^{1,6,7^{*}}$

${ }^{1}$ Department of Anesthesiology, Duke University School of Medicine, Durham, NC;

${ }^{2}$ Department of Biochemistry and Molecular Biology, Saint Louis University,

St. Louis, Missouri;

${ }^{3}$ Division of Laboratory Sciences, National Center for Environmental Health, Centers for Disease Control and Prevention, Atlanta, GA 30341, USA

${ }^{4}$ Center for Free Radical Biology and Lung Injury and Repair Center, The University of Alabama at Birmingham, Birmingham, Alabama

${ }^{5}$ Department of Medicine, Duke University School of Medicine, Durham, NC;

${ }^{6}$ Department of Pharmacology and Cancer Biology, Duke University School of Medicine, Durham, NC

${ }^{7}$ Integrated Toxicology \& Environmental Health Program, Duke University, Durham, NC

${ }^{a}$ Current affiliation: San Juan Laboratory, Office of Medical Products and Specialty Laboratory Operations, Office of Regulatory Science, Office of Regulatory Affairs, U.S. Food and Drug Administration, 466 Fernandez Juncos Ave. San Juan, Puerto Rico, 00901, USA

*Address for reprints and other correspondence:

Sven-Eric Jordt (Email: sven.jordt@duke.edu)

Satyanarayana Achanta (Email: satya.achanta@duke.edu)

Department of Anesthesiology, Duke University School of Medicine

Box 3094, MS27, Durham, NC 27710-3094

Phone: +19196841327

Fax: +1 9196842411 


\section{Abstract}

Rationale: Chlorine gas $\left(\mathrm{Cl}_{2}\right)$ has been repeatedly used as a chemical weapon, first in World War I and most recently in Syria. Life-threatening $\mathrm{Cl}_{2}$ exposures frequently occur in domestic and occupational environments, and in transportation accidents. There is a knowledge gap in large animal models of $\mathrm{Cl}_{2}$-induced acute lung injury ( $\mathrm{ALI}$ ) required to accurately model human etiology and for the development of targeted countermeasures

Objective: To develop a translational model of $\mathrm{Cl}_{2}$-induced $\mathrm{ALI}$ in swine to study toxicopathophysiology and identify biomarkers useful for forensic analysis.

Methods: Specific pathogen-free Yorkshire swine $\left(30-40 \mathrm{~kg}\right.$ ) of either sex were exposed to $\mathrm{Cl}_{2}$ gas $(\leq 240 \mathrm{ppm}$ for $1 \mathrm{~h})$ or filtered air under anesthesia and controlled mechanical ventilation.

Results: Exposure to $\mathrm{Cl}_{2}$ resulted in severe hypoxia and hypoxemia, increased airway resistance and peak inspiratory pressure, and decreased dynamic lung compliance. Chlorine exposure resulted in increased total BALF and neutrophil counts, vascular leakage, and edema compared to the control group. The model recapitulated all three key histopathological features of human ALI, such as neutrophilic alveolitis, deposition of hyaline membranes, and formation of microthrombi. Free and lipid-bound 2-chlorofatty acids and chlorotyrosine-modified proteins (3chloro-L-tyrosine and 3,5-dichloro-L-tyrosine) were detected in plasma and lung after $\mathrm{Cl}_{2}$-exposure.

Conclusions: The translational model developed in this study replicates key features of humans exposed to $\mathrm{Cl}_{2}$ and is suitable to test medical countermeasures. Specific biomarkers of $\mathrm{Cl}_{2}$ exposure have been identified in plasma and lung tissue samples.

Keywords: chlorine, acute lung injury, chemical countermeasure, 21 CFR 314.600, pig translational model 


\section{Take home message}

We developed a swine model of chlorine gas-induced acute lung injury that exhibits several

features of human acute respiratory distress syndrome. We validated chlorinated fatty acids and protein adducts in plasma and lung samples as forensic biomarkers. 


\section{INTRODUCTION}

Chlorine gas $\left(\mathrm{Cl}_{2}\right)$ is a highly reactive toxic halogen. Chlorine gas is safe for several domestic, occupational, and industrial purposes when used at appropriate concentrations. However, it can be toxic when used inappropriately. $\mathrm{Cl}_{2}$ has been used as a chemical weapon since World War I and most recently in chlorine bomb attacks in Syria $[1,2]$. The UN-supported OPCW factfinding missions proved that Syria used $\mathrm{Cl}_{2}$ allegedly on the civilian population [2]. $\mathrm{Since} \mathrm{Cl}_{2}$ can be easily synthesized from simple ingredients, $\mathrm{Cl}_{2}$ has resurged as a potential chemical warfare agent. Unfortunately, biomarkers that can confirm $\mathrm{Cl}_{2}$ exposure have only been validated in in vitro and rodent models [3-6].

Train derailments have been sources of accidental exposure to toxic concentrations of $\mathrm{Cl}_{2}$. Several major cargo derailments and other transportation accidents have occurred throughout the world, resulting in morbidity and mortality [7-11]. It is estimated that chlorine accounts for $84 \%$ of the total toxic inhalation hazards (TIH) transported every year [12]. The train derailment incident in Graniteville, $\mathrm{SC}$ in 2005 is considered one of the largest $\mathrm{Cl}_{2}$ accidents in the United States. In that incident, 9 people died and 200 were admitted for inhalational pulmonary injuries $[7,9,10,13]$. In addition to acute casualties, long-term inflammation and hyperreactivity have also been reported in victims of the Graniteville derailment $[10,14,15]$.

The pathophysiology and symptoms of acute lung injury (ALI) caused by $\mathrm{Cl}_{2}$ are highly variable, and based on concentration and exposure time [16-19]. The common acute symptoms of $\mathrm{Cl}_{2}$ inhalation are consistent with an acute respiratory impairment, and include running nose, sore throat, cough, choking, tightness of chest, labored breathing, bronchospasms, and wheezing $[7,17,20]$. Exposure to higher concentrations of $\mathrm{Cl}_{2}$ for a prolonged period may result in non- 
cardiogenic edema. At concentrations above $1000 \mathrm{ppm}, \mathrm{Cl}_{2}$ can be fatal to humans within a few minutes [18, 21].

Due to increased concerns about the use of $\mathrm{Cl}_{2}$ as a potential chemical threat agent and the likelihood of accidental and occupational exposures, there is an immediate need for therapeutic agent(s) against $\mathrm{Cl}_{2}$-induced ALI. Plume models have predicted the gravity of a $\mathrm{Cl}_{2}$ attack or accidental release [22-24]. Despite the use of $\mathrm{Cl}_{2}$ as a chemical warfare agent since World War I, there is no specific antidote for this powerful choking agent except symptomatic treatment $[17,19]$. Although several potential therapeutic agents have been tested for efficacy in $\mathrm{Cl}_{2}$-induced $\mathrm{ALI}$ in different preclinical animal models, none have been approved $[19,25,26]$. Due to ethical and feasibility issues surrounding clinical trials of chemical threat agents in humans, the United States Food and Drug Administration (FDA) made provisions to approve therapeutic agents under animal rule (21 CFR 314.600) [27]. Animal rule recommends demonstration of therapeutic efficacy in at least 2 animal models, including a higher mammalian species close to humans in phylogeny. Rodent models have been routinely used to screen for the initial therapeutic efficacy of candidate drugs $[19,28]$. However, no ideal large animal model that mimics several features of human $\mathrm{Cl}_{2}$-induced ALI/ARDS (acute respiratory distress syndrome) has yet been developed, which remains a barrier to testing potential therapeutic candidates. Therefore, we developed a pig translational model of human chlorine gas-induced ALI, and validated chlorinated fatty acids and chlorinated tyrosine adducts as potential biomarkers of $\mathrm{Cl}_{2}$ exposure. We chose the pig as a translational model to study chemically induced ALI in humans due to their anatomic and physiologic similarities [29, 30].

\section{MATERIALS AND METHODS}

Please see additional details on materials and methods in the online supplementary information. 
Preparation of animals, $\mathrm{Cl}_{2}$ exposure, and data collection: Specific pathogen-free (SPF) male and female Yorkshire pigs $(\mathrm{n}=14)$ (castrated males and intact females) $(30-40 \mathrm{~kg})$ were procured, and given at least 48 hours to acclimate. The Duke University Institutional Animal Care and Use Committee (IACUC) approved the procedures in this study.

Animals were anesthetized and mechanically ventilated. After placement of surgical instrumentation and acquisition of baseline data (respiratory and cardiovascular physiologic parameters, and arterial blood gas analysis), animals were randomized to $\mathrm{Cl}_{2}$ or filtered room air exposure (n=6/air group; $8 / \mathrm{Cl}_{2}$ group). (Two pigs died during or a few hours after $\mathrm{Cl}_{2}$ exposure; therefore, data were presented for 6/group.) $\mathrm{Cl}_{2}$ was delivered via the inspiratory limb of the mechanical ventilator circuit, and monitored with a chlorine detector (Porta Sense II Gas Leak Detector, AFC International, Inc, DeMotte, IN, USA) at 8-15-minute intervals to ensure delivery of $\leq 240$ ppm for 1 hour. $\mathrm{Cl}_{2}$ exposure occurred in a negatively pressurized room with adequate ventilation and safety monitoring for leak detection in multiple locations. Figures $1 \mathrm{~A}$ and $1 \mathrm{~B}$ show the study paradigm and the schematic of the $\mathrm{Cl}_{2}$ exposure system for pigs.

We collected complete blood counts (CBC) and serum chemistry panel values at baseline and at 24 hours post exposure. The key respiratory physiologic parameters were recorded and arterial blood gas analysis was performed at 5 and 30 minutes post exposure, and then subsequently at 1hour intervals until euthanasia at 24 hours post exposure. Oxygenation parameters, ie, the ratio of the partial pressure of oxygen in arterial blood and fraction of inhaled oxygen $\left(\mathrm{PaO}_{2} / \mathrm{FiO}_{2}\right)$, oxygenation index, saturation of oxygen in hemoglobin, and arterial-alveolar (A-a) gradient, were primarily considered. Respiratory physiologic parameters, such as compliance dynamics $\left(\mathrm{C}_{\mathrm{dyn}}\right)$, airway resistance (Raw), and peak inspiratory pressure (PIP), were assessed at hourly intervals. At 24 hours post $\mathrm{Cl}_{2}$ or air exposure, airway mechanics were measured by challenging 
pigs to increasing concentrations of methacholine hydrochloride $(\mathrm{MeCh})(0,0.5,1,2,4,8,16$, and $32 \mathrm{mg} / \mathrm{mL}$ ) (Sigma-Aldrich, St. Louis, MO, USA) via an Aeroneb ${ }^{\mathrm{TM}}$ nebulizer (Aerogen Ltd, Ireland). Bronchoscopy was performed to collect bronchoalveolar lavage fluid (BALF) just before euthanasia, and total and differential leukocyte counts were determined as previously published, with some modifications [28].

At the end of the 24-hour period, we euthanized pigs following AVMA guidelines on euthanasia, and collected lung tissues for histopathology and diagnostic marker analysis. A board-certified veterinary pathologist performed blinded histopathologic scoring of lung specimens following an official American Thoracic Society (ATS) Workshop Report: Features and Measurements of Experimental Acute Lung Injury in Animals, with some modifications (Table S1)[31]. We determined edema using lung wet/dry weight ratio as a surrogate marker. Concentrations of proinflammatory cytokine markers were determined in BALF supernatants, serum samples, and lung tissue homogenates using ELISA kits (R\&D Systems, Minneapolis, MN, USA).

Chlorinated fatty acids (CFAs) in lungs and plasma: Free and total (ie, free + esterified) 2chlorofatty acids were measured, as previously described, by LC/MS following Dole extraction [32]. Total 2-chlorofatty acids were measured by LC/MS after base hydrolysis, while free 2chlorofatty acids were not subjected to base hydrolysis before LC/MS analysis. Extractions were performed using $25 \mu \mathrm{L}$ of plasma spiked with $103.5 \mathrm{fmol}$ of 2 -chloro-[d4-7,7,8,8]-palmitic acid (2-[d4]-ClPA) as the internal standard. Lung tissue $(20 \mathrm{mg})$ was pulverized and subjected to Bligh-Dyer lipid extraction [33] in the presence of 103.5 fmol of 2-[d4]-ClPA (internal standard). Half of the lung lipid extract was then analyzed by LC/MS for free 2-chlorofatty acids, and the other half of the extract was subjected to base hydrolysis followed by LC/MS analysis for total 2-chlorofatty acids. 
Chlorinated tyrosine adducts (CTAs) in plasma and lung tissues: The biomarkers 3-chlorotyrosine (Cl-Tyr) and 3,5-dichlorotyrosine (Cl2-Tyr) were isolated from the pronase digest of plasma and lung tissues samples from air or chlorine exposed pigs by solid-phase extraction (SPE), separated by reversedphase HPLC and detected by tandem mass spectrometry (MS-MS), following previously published methods $[34,35]$.

Data and statistical analysis: Data are presented as the mean \pm standard error of mean estimate $(\mathrm{SEM})$ in figures and as mean \pm standard deviation $(\mathrm{SD})$ in tables. Oxygenation and respiratory physiologic parameters are presented as time course scatter plots over 24 hours, and bar graphs represent area under the curve (AUC) from post- $\mathrm{Cl}_{2}$ or -air exposure through 24 hours. Unpaired Student's $t$-test (two-tailed) was performed for comparison of means of 2 groups for statistical analysis unless mentioned (GraphPad Prism version 9 for Windows, GraphPad Software, San Diego, California USA). An $\alpha$ value $<0.05$ was considered significant. Statistical significance was denoted as: $* p \leq 0.05 ; * * p \leq 0.01 ; * * * p \leq 0.001 ; * * * *<<0.0001$.

\section{RESULTS}

We chose a combination of $240 \mathrm{ppm}$ for the concentration of $\mathrm{Cl}_{2}$ and 1 hour for time of exposure based on our initial chlorine exposure-response studies. Figure $1 \mathrm{C}$ shows interday variability and precision of $\mathrm{Cl}_{2}$ exposure. The interday precision of $\mathrm{AUC}$ of $\mathrm{Cl}_{2}$ exposure was $4.8 \%$.

Complete blood counts and serum chemistry panels: CBC and serum chemistry panel values are presented in Tables S3 and S4, respectively. Platelets had significantly decreased in both groups at 24 hours post exposure compared to their respective baseline values. Also, the mean platelet count was different between air- and $\mathrm{Cl}_{2}$-exposed groups at the 24-hour time point. 
Although other parameters had some trends in complete blood counts, they did not reach statistical significance. Among serum chemistry panel values, there was no significant difference between air- and $\mathrm{Cl}_{2}$-exposed groups at the 24-hour time point. However, there was a significant difference between values at baseline and the 24-hour time point for glucose, cholesterol and alkaline phosphatase in both air- and $\mathrm{Cl}_{2}$-exposed groups. As there are no published references for $\mathrm{CBC}$ and serum chemistry in a pig model of $\mathrm{Cl}_{2}$ inhalation injury, the data presented here will serve as a reference for future work.

Acid-base imbalance in $\boldsymbol{C l}_{2}$ exposed pigs: In the $\mathrm{Cl}_{2}$ group, immediately after gas exposure, the $\mathrm{pH}$ and $\mathrm{HCO}_{3}{ }^{-}$fell, and partial pressure of carbon dioxide in the arterial blood $\left(\mathrm{PaCO}_{2}\right)$ increased. Therefore, the initial acid-base imbalance suggests respiratory acidosis with metabolic acidosis. Due to a compensatory increase in $\mathrm{HCO}_{3}{ }^{-}$, the $\mathrm{pH}$ increased, and then decreased toward the end of the study. However, over 24 hour observation, no significant difference in AUCs of pH was noted between the air and chlorine groups; The $\mathrm{PaCO}_{2}$ and $\mathrm{HCO}_{3}{ }^{-}$were decreased in the chlorine-exposed group whereas lactate values increased (Figure S1). The resulting acid-base imbalance over 24 hour suggests respiratory alkalosis with metabolic acidosis.

Oxygenation parameters: Pigs in both groups started with identical oxygenation parameters. $\mathrm{Cl}_{2}$ exposure resulted in immediate hypoxia and hypoxemia. Pigs in both groups were mechanically ventilated with $21 \%$ oxygen, and $\mathrm{FiO}_{2}$ was adjusted to maintain at least $80 \%$ oxygen saturation in hemoglobin $\left(\mathrm{SpO}_{2}\right)$. Pigs in the chlorine group required higher $\mathrm{FiO}_{2}$ values $(95 \%$ confidence intervals $[\mathrm{CI}]$ of AUC, 5.56-6.6) compared to the air group (95\% CI of AUC, 5.0-5.1) to maintain $\mathrm{SpO} 2$ values above $80 \%$ (Fig. 2A). $\mathrm{SpO}_{2} / \mathrm{FiO}_{2}$ values in the chlorine group (95\% CI of AUC, 8580-9776) were significantly decreased compared to the air group (95\% CI, 1076410999) (Fig. 2B). $\mathrm{PaO}_{2} / \mathrm{FiO}_{2}$ values in the chlorine group (95\% CI of AUC, 5663-6777) were 
significantly lower than in the air group (95\% CI, 9013-9343) (Fig. 2C). The oxygenation index (OI) was significantly increased in the chlorine group (95\% CI of AUC, 105-145) vs the air group (95\% CI, 49.4-54.3) (Fig. 2D). The arterial-alveolar (A-a) gradient was significantly elevated in the chlorine group (95\% CI of AUC, 1303-2020) compared to the air group (95\% CI, 224-355) (Fig. 2E).

Respiratory physiologic parameters: Pigs in both groups had similar baseline respiratory physiologic parameters. Airway resistance was significantly increased in the chlorine group (95\% CI of AUC, 332-459) compared to the air group (95\% CI, 152-182) (Fig. 3A). Similarly, peak inspiratory pressure was significantly increased in the chlorine group (95\% CI of AUC, 645-764) vs the air group (95\% CI, 378-419) (Fig. 3B). Compliance dynamics was significantly decreased in the chlorine group (95\% CI of AUC, 306-357) compared to the air group (95\% CI, 583-673) (Fig. 3C).

Methacholine airway challenge: At 24 hours post exposure, the $\mathrm{Cl}_{2}$ group displayed heightened basal pulmonary resistance compared to the air group. Figures 4A-C show responses in airway

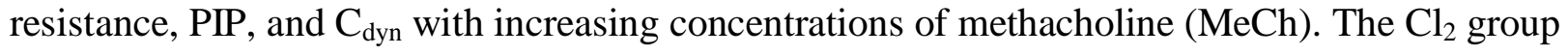
exhibited airway hyperreactivity to inhaled $\mathrm{MeCh}$, whereas the air group tolerated higher concentrations of $\mathrm{MeCh}$.

BALF total cell counts and differential leukocyte counts, protein leak, and edema: The total BALF leukocyte count was significantly increased in $\mathrm{Cl}_{2}$ pigs compared to the air group (Fig. S2A). BALF protein levels and wet/dry lung weight ratio were significantly increased in the $\mathrm{Cl}_{2}$ group compared to the air group (Fig. S2B and S2C). 
Pro-inflammatory cytokine markers: IL-6 and VEGF levels were increased in $\mathrm{Cl}_{2}$ pigs in all three biological matrices tested, ie, BALF, serum, and lung tissue homogenates (Fig. S2D-F).

Postmortem examination and histopathologic analysis: Postmortem gross examination of the lungs revealed diffuse lesions of atelectasis and hemorrhage in the $\mathrm{Cl}_{2}$ group, whereas the air group had no detectable abnormal findings. However, caudal atelectatic lesions were found in the lungs of both groups. Such lesions are consistent with mechanical ventilator-induced lung injury (VILI). In pigs exposed to air, histopathologic analysis of the lungs revealed normal open alveolar architecture of the parenchyma without any significant lesions. In pigs exposed to $\mathrm{Cl}_{2}$, however, lung sections showed partial to complete occlusion of the alveolar air spaces by neutrophils and macrophages as well as thickening of the alveolar septa by similar inflammatory cells and edema, and some of the alveolar spaces exhibited protein (either fluid or fibrin). Histopathologic scores were significantly higher in $\mathrm{Cl}_{2}$ pigs compared to the air group (Fig. 5A). In $\mathrm{Cl}_{2}$ pigs, the tracheal mucosa was completely disrupted and overlaid with cell debris, whereas histopathologic analysis of the trachea from the air group showed normal architecture (Fig. 5B).

Chlorinated fatty acids: Free and total (ie, free + esterified) 2-chlorofatty acids were detected in plasma and lung tissues from both groups. Free fatty acids (2-chloropalmitic acid, 16:0 Cl and 2chlorostearic acid, 18:0 Cl), which are not esterified to complex lipids, were significantly increased in plasma samples collected within 2 hours after chlorine exposure (Figure 6A), whereas total fatty acids $(16: 0 \mathrm{Cl}$ and 18:0 Cl) were significantly increased in plasma samples that were collected up to 24 hours after chlorine exposure compared to correspondingly timed samples from pigs in the air group (Figure 6B). Both free and total 2-chloropalmitic acid and 2chlorostearic acid were significantly increased in lung tissue harvested at 24 hours after chlorine exposure compared to air exposure (Figure 6C-D). 
Chlorinated tyrosine adducts: An analytical method to quantify Cl-Tyr and $\mathrm{Cl}_{2}$-Tyr in pig lung and plasma tissues was established (Table S2 and Figure S3). Concentrations of Cl-Tyr and $\mathrm{Cl}_{2^{-}}$ Tyr remained either close to lower reportable level (LRL) or undetectable in both plasma and lung tissue samples collected from air-exposed pigs whereas the concentrations have significantly increased in $\mathrm{Cl}_{2}$-exposed pigs by several folds (Figure 7).

\section{DISCUSSION}

In this study, we developed a human translational model of ALI in swine to meet the US FDA's animal rule for the Chemical Medical Countermeasures Program [27]. The model described here overcomes several limitations described in the previously published literature [3640]. The $\mathrm{AUC}$ of $\mathrm{Cl}_{2}$ exposure in this model was $12118 \pm 584$ ppm.min (mean $\pm \mathrm{SD}$ ), which correlates with fatal exposure in humans (> $400 \mathrm{ppm}$ of $\mathrm{Cl}_{2}$ for 30 minutes, that is, 12000 ppm.min) [18]. Therefore, the swine model described in this study represents victims exposed to fatal concentrations of $\mathrm{Cl}_{2}$.

Although the literature review shows some reports on $\mathrm{Cl}_{2}$-induced ALI models in pig and sheep, those reports acknowledged limitations in their models [37-43]. We admit that no animal model is completely devoid of limitations. However, our model overcomes most of the limitations of previously published swine models. In contrast to the previously published models, we used a 5-cm $\mathrm{H}_{2} \mathrm{O}$ positive end-expiratory pressure (PEEP) to prevent the collapse of alveoli during exhalation, and to improve alveolar recruitment and oxygenation capacity [36-39]. While the accepted range of tidal volume $(\mathrm{TV})$ is $6-8 \mathrm{~mL} / \mathrm{kg}$, previously published literature used TV outside the accepted volumes, ranging from 8-10 mL/kg [37], $10 \mathrm{~mL} / \mathrm{kg}$ [39], 15-20 mL/kg [36], and $12 \mathrm{~mL} / \mathrm{kg}$ [38], whereas we used $7 \mathrm{~mL} / \mathrm{kg}$. In previous studies, pigs were exposed to $\mathrm{Cl}_{2}$ at concentrations ranging from 100-140 ppm for 10 minutes (1000-1400 ppm.min) to 400 ppm for 
15-20 minutes (6000-8000 ppm.min), whereas we used 240 ppm for 60 minutes (14400 ppm.min). We studied the pathophysiology of $\mathrm{Cl}_{2}$-induced ALI in pigs for 24 hours, whereas the available literature shows studies spanning over 5 hours. We maintained pigs on pressureregulated volume control and assist control (PRVC A/C) mode of mechanical ventilation. In PRVC mode, the preset tidal volume is maintained by adapting to the changing compliance of the lungs to adjust inspiratory time and pressure. As assist control is also engaged in this setting, respiration is completely under the control of the mechanical ventilator.

Acid-base imbalance: Previous clinical trials and pre-clinical studies suggested respiratory acidosis with exposure to $\mathrm{Cl}_{2}$, and further, intravenous or nebulized sodium bicarbonate $\left(\mathrm{NaHCO}_{3}\right)$ has been used as a therapeutic agent to correct the acid-base imbalance. However, the evidence is mostly anecdotal, or at best, limited data are available to support this treatment $[18,44]$. In the current study, we noted change acid-base imbalance from respiratory acidosis with metabolic acidosis initially after the end of $\mathrm{Cl} 2$ exposure and overall interpretation suggests respiratory alkalosis with metabolic acidosis. The increased lactate levels in $\mathrm{Cl}_{2}$-exposed pigs clearly suggest hypoxia and injury. The anesthesia protocol and mechanical ventilation may have had some influence on the acid-base imbalance. The lack of normal values for arterial blood gas analysis in pigs also makes it difficult to compare with human values. Therefore, the data should be interpreted with caution. Together, these findings suggest that generalized treatment of $\mathrm{Cl}_{2}$ victims with $\mathrm{NaHCO}_{3}$ may not be the Holy Grail, but still important for management of acidbase imbalance.

Oxygenation parameters: Exposure to $\mathrm{Cl}_{2}$ resulted in immediate hypoxia and hypoxemia. The $\mathrm{P} / \mathrm{F}$ ratio, also called the Carrico index, is a comparison between the oxygen level in the blood and the concentration of inhaled oxygen. The $\mathrm{P} / \mathrm{F}$ ratio is generally used in critical care medicine 
to assess oxygenation in patients. $\mathrm{PaO}_{2} / \mathrm{FiO}_{2} \leq 300$ and $\leq 200 \mathrm{mmHg}$ are signs of ALI and ARDS, respectively [45]. P/F ratio values had decreased below 300 in our chlorine group at the end of $\mathrm{Cl}_{2}$ exposure, and remained the same or decreased further over the following 24 hours. Oxygenation index $(\mathrm{OI})$ is recognized as a more sensitive marker than the $\mathrm{P} / \mathrm{F}$ ratio for assessing oxygenation because lung mechanics (mean airway pressure) is considered in the calculation. Lower OI values indicate better utilization of inhaled oxygen, and are desirable. Our $\mathrm{Cl}_{2}$-exposed pigs had higher OI values. $\mathrm{SpO}_{2}$ indicates oxygen saturation levels in hemoglobin. We started all pigs at room air $\left(\mathrm{FiO}_{2}\right.$ of $\left.21 \%\right)$; however, we adjusted $\mathrm{FiO}_{2}$ to maintain at least $80 \% \mathrm{SpO}_{2}$. The $\mathrm{Cl}_{2}$ group required higher $\mathrm{FiO}_{2}$ to maintain at least $80 \% \mathrm{SpO}_{2}$ compared to the air group. As higher $\mathrm{FiO}_{2}$ values can result in the production of more reactive oxygen species, we tried to maintain a modest value of at least $80 \% \mathrm{SpO}_{2}$. Targeting a higher $\mathrm{SpO}_{2}$ value by increasing $\mathrm{FiO}_{2}$ might be useful, but no controlled studies are available to support this idea, and supplementing higher $\mathrm{FiO}_{2}$ value has been linked to worsening ALI [46]. A-a gradient values were higher in the chlorine group vs the air group. Elevated A-a gradient values indicate that oxygen is not effectively transferred from the alveoli to the blood, and suggest a defect in diffusion and a ventilation-perfusion mismatch. This is not a surprising finding, as previous studies have shown that alveoli are damaged with $\mathrm{Cl}_{2}$ exposure.

Respiratory physiologic parameters: Airway resistance and PIP increased significantly in $\mathrm{Cl}_{2-}$ exposed pigs. $\mathrm{C}_{\mathrm{dyn}}$ decreased rapidly following $\mathrm{Cl}_{2}$ exposure. This rapid decrease in $\mathrm{C}_{\mathrm{dyn}}$ may be due to increased resistance to airflow, resulting in regional trapping of air with hyperinflation of lung regions distal to the site of bronchoconstriction. The collapse of pulmonary parenchyma and increase in interstitial fluids may also decrease $C_{d y n}$ at later stages of ALI $[38,47]$. In the methacholine airway challenge test, control animals tolerated higher concentrations of 
methacholine, suggesting airway hyperreactivity in $\mathrm{Cl}_{2}$-exposed animals. Further, there was a clear difference in baseline values between the 2 groups before administration of the first dose of methacholine, which is commonly not noted in rodent models of ALI.

Pro-inflammatory cytokine markers: Pro-inflammatory cytokine markers, such as IL-6 and VEGF, were increased in the chlorine group compared to control animals. IL-6 values were consistently increased after $\mathrm{Cl}_{2}$ exposure in all 3 biological matrices tested. Therefore, IL-6 may be useful as a potential pro-inflammatory cytokine marker to assess disease progression as well as therapeutic efficacy of drug candidates.

Effects on cardiovascular function: One pig died during $\mathrm{Cl}_{2}$ exposure, and another pig died 3-4 hours after $\mathrm{Cl}_{2}$ exposure. Both died rapidly without displaying any symptoms except progressive non-responsive hypotension, decreased heart rate, and hypoxemia. Cardiopulmonary resuscitation (CPR) efforts with $100 \%$ oxygen supplementation, epinephrine injection and defibrillation were not successful. A postmortem examination revealed that both pigs had preexisting left ventricular hypertrophy (right-to-left ventricular wall thickness ratio $\geq 1: 5$ ). Previous studies show that cardiac ventricular hypertrophy is a common finding in pigs that is based on the birth season, breed, sex, and sire family $[48,49]$. This suggests that $\mathrm{Cl}_{2}$ exposure in the context of pre-existing cardiac dysfunction can result in severe casualties. $\mathrm{Cl}_{2}$ exposure decreases cardiac output probably due to right ventricular failure secondary to pulmonary vasoconstriction [38]. Often, severe right ventricular failure results in death, particularly in patients with preexisting left ventricular failure or left ventricular hypertrophy. Limited animal studies and isolated reports in humans exposed to $\mathrm{Cl}_{2}$ suggest effects on the cardiovascular system [50]. Additional detailed studies on cardiovascular effects are warranted. 
Postmortem lung gross examination and histopathology: Gross examination of the lungs revealed diffuse atelectatic lesions in the diaphragmatic lobes of both groups. These findings are consistent with the lesions commonly seen in animals restrained in dorsal recumbency (supine positioning) and mechanically ventilated. In this study, animals were mechanically ventilated in the supine position, which is one of the limitations of the study. Prone positioning was shown to be advantageous over supine positioning in both human studies and translational animal models $[38,51-53]$. Future studies are warranted to prospectively study the advantages of prone positioning and positional maneuvers in $\mathrm{Cl}_{2}$-exposed pigs. The $\mathrm{Cl}_{2}$-exposed lung tissues exhibited all 3 key features of human ALI: neutrophilic alveolitis, deposition of hyaline membranes, and formation of microthrombi. Therefore, this animal model can be used to study other forms of ALI in humans [30, 31].

CFAs and CTAs: There are no diagnostic markers for $\mathrm{Cl}_{2}$-exposed victims. The current literature on diagnostic markers is limited to pre-clinical studies, particularly in rodent models or in vitro studies [3-6, 34]. Free and total CFAs (2-chloropalmititc acid and 2-chlorostearic acid) were significantly increased in both plasma and lung tissues collected from the $\mathrm{Cl}_{2}$ group, suggesting that they may be used as diagnostic markers. Both free and total 2-chloropalmitic and 2chlorostearic acids were significantly increased immediately after exposure to $\mathrm{Cl}_{2}$, and decreased over the following 24 hours. However, the levels remained several-fold higher until 24 hours after $\mathrm{Cl}_{2}$ exposure. We expect that CFA levels remain higher by several fold until 72 hours post exposure or beyond, as seen in rodent studies [3]. These chlorinated lipids are produced when $\mathrm{Cl}_{2}$ or hypochlorite reacts with plasmalogen. Previously, in rodent models of $\mathrm{Cl}_{2}$-induced ALI, chlorinated lipids such as 2-chloropalmitaldehyde (2-Cl-Pald), 2-chlorostearaldehyde (2-ClSald), and their oxidized products, free- and esterified 2-chloropalmitic acid (2-Cl-PA) and 2- 
chlorostearic acid were detected in the lungs and plasma [3, 54]. Previously CTAs (Cl-Tyr and C12-Tyr) have been detected in various mouse biological matrices, and in human blood samples under in vitro conditions $[34,35]$. Overall, $\mathrm{Cl}$-Tyr and $\mathrm{Cl}_{2}$-Tyr concentrations were undetectable or remained below lower reportable level (LRL) in both plasma and lung tissue samples collected from air-exposed pigs whereas the concentrations were detectable or several folds higher in plasma and lung tissue samples collected from chlorine-exposed pigs. Thus, the findings in plasma and lung tissues of our porcine model corroborate with previous findings in rodents. Detection of CFAs and CTAs independently in 2 animal models of $\mathrm{Cl}_{2}$-induced ALI strongly suggests their utility as potential biomarkers. Particularly, detection of CFAs and CTAs in plasma samples until 24 hours is advantageous from a forensic point of view, and the ease of sample collection at multiple time points is also advantageous. Detection of CFAs and CTAs in lung tissue samples is also highly relevant from a forensic point of view in establishing that victims indeed died of $\mathrm{Cl}_{2}$ exposure.

\section{Clinical applicability}

The actual pathophysiologic course of human victims exposed to $\mathrm{Cl}_{2}$ is highly variable depending on the concentration of the gas, duration of exposure, and distance of the individual victim from the locus of the source. This model represents several features of humans exposed to fatal concentrations of $\mathrm{Cl}_{2}$. When a human is exposed to $\mathrm{Cl}_{2}$, the victim runs, and under those horrified panic situations, the victim breathes through the oropharynx. Several diffusion modeling studies at low $\mathrm{Cl}_{2}$ concentrations suggest that $\sim 90 \%$ of inhaled $\mathrm{Cl}_{2}$ will be scrubbed in the nasal passages and pharynx, and that only $10 \%$ of inhaled $\mathrm{Cl}_{2}$ reaches beyond the hypopharynx [55]. In our model, pigs were exposed to $\mathrm{Cl}_{2}$ via an endotracheal tube not only to ensure homogenous exposure but also to replicate human $\mathrm{Cl}_{2}$ exposure. 


\section{Limitations of the study}

We limited our study observation time to 24 hours. However, in the continuum of this work, it would be worthwhile to extubate the animals after $\mathrm{Cl}_{2}$ exposure, and monitor them over extended time, at least up to 2 months. Animals under continued mechanical ventilation and anesthesia fail to exhibit their natural physiologic protective reflexes such as cough, apnea, and shallow breathing [38]. Therefore, studies are warranted to understand the long-term pathophysiology of $\mathrm{Cl}_{2}$-exposed and extubated pigs.

\section{CONCLUSIONS}

We recapitulated the pathophysiologic course of $\mathrm{Cl}_{2}$ on the pulmonary system in pigs, and demonstrated that our pig model of acute lung injury serves as an excellent translational model of human $\mathrm{Cl}_{2}$-induced ALI for developing/screening potential chemical countermeasures. Further, we identified biomarkers of chlorine exposure.

\section{Acknowledgments}

Authors would like to thank Dr Michael Foster, PhD, for his thoughtful discussions in setting up our chlorine exposure system; Ianthia E Parker, George Quick, Michael Lowe, and Christie Holmes for their assistance in pig studies; Dr Jerry Ritchey, DVM, PhD, DACVP, Center for Veterinary Health Sciences, Oklahoma State University, for blinded histopathologic analysis.

\section{DISCLOSURES}

No conflicts of interest, financial or otherwise, are declared by the author(s).

SA and S-EJ are supported by a cooperative agreement U01ES030672-01 and 1R21ES030331-

01A1 of the NIH Countermeasures Against Chemical Threats (CounterACT) program. DAF was 
supported by National Institutes of Health grants R01GM115553. The content is solely the responsibility of the authors, and does not necessarily represent the views of the NIH.

\section{AUTHOR CONTRIBUTIONS}

SA and S-EJ conceived and designed research; SA and MG performed animal experiments; CJA, KAS, DAF, and RPP performed chlorinated fatty acid analyses; BSC, JQG, JWP, and TAB performed chlorinated tyrosine adduct analyses; SA and S-EJ analyzed data and interpreted experimental results; SA prepared figures and wrote the first draft of manuscript; SA and S-EJ edited and revised manuscript; SA and S-EJ approved final version of manuscript. 


\section{FIGURE LEGENDS}

Figure 1: Study design paradigm (1A), chlorine gas exposure schematic (1B), and interday precision of chlorine gas exposure (1C). Anesthetized and mechanically ventilated pigs were exposed to either chlorine gas at $\leq 240 \mathrm{ppm}$ or filtered room air for 1 hour. Chlorine exposure was monitored every 8-15 minutes. Arterial blood gas analysis was performed at hourly intervals, and all key oxygenation and respiratory physiologic parameters were recorded. At 24 hours post chlorine gas or filtered air exposure, methacholine airway challenge was performed, bronchoalveolar lavage fluid was collected with the aid of bronchoscopy, and pigs were then euthanized to conduct gross necropsy and sample collection.

Figure 2: Oxygenation parameters in chlorine-exposed pigs. Anesthetized and mechanically ventilated pigs were exposed to either chlorine gas at $\leq 240 \mathrm{ppm}$ or filtered room air for 1 hour. The fraction of inhaled oxygen $\left(\mathrm{FiO}_{2}\right)(\mathrm{Fig} 2 \mathrm{~A})$, oxygen saturation in hemoglobin normalized by $\mathrm{FiO}_{2}\left(\mathrm{SpO}_{2} / \mathrm{FiO}_{2}\right)(\mathrm{Fig} 2 \mathrm{~B})$, the ratio of partial pressure of oxygen to fraction of inhaled oxygen $\left(\mathrm{PaO}_{2} / \mathrm{FiO}_{2}\right)$ (Fig 2C), oxygenation index (Fig 2D), and arterial-alveolar (A-a) gradient (Fig 2E) were measured at hourly intervals. The time-course scatter plots show the dynamics of the oxygenation parameters over the 24-hour study period. Bar graphs show the area under the curve over the 24-hour study period, and were compared by unpaired two-tailed $t$-test. $* * * *, p<$ 0.0001 .

Figure 3: Pulmonary physiologic parameters in chlorine-exposed pigs. Anesthetized and mechanically ventilated pigs were exposed to either chlorine gas at $\leq 240 \mathrm{ppm}$ or filtered room air for 1 hour. Airway resistance (Fig 3A), peak inspiratory pressure (PIP) (Fig 3B), and compliance dynamics $\left(\mathrm{C}_{\text {dyn }}\right)$ (Fig 3C) were measured at hourly intervals. The time-course scatter plots show trends in pulmonary physiologic parameters over the 24-hour study period. Bar 
graphs show the area under the curve over the 24-hour study period, and were compared by unpaired two-tailed $t$-test. $* * * *, p<0.0001$.

Figure 4: Pulmonary mechanics in chlorine-exposed pigs. Methacholine airway challenge was conducted to assess airway mechanics in chlorine- or air-exposed pigs. Airway resistance (Fig 4A), peak inspiratory pressure (PIP) (Fig 4B), and compliance dynamics $\left(\mathrm{C}_{\text {dyn }}\right)($ Fig $4 \mathrm{C})$ were measured. Unpaired two-tailed $t$-tests were performed between chlorine and air groups at each concentration of methacholine. $\mathrm{n}=6 / \mathrm{Cl}_{2}$-exposed and $5 /$ air-exposed pigs. ${ }^{*}, p<0.05 ;{ }^{\#}, p<$ $0.01 ; \stackrel{\$}{\$}, p<0.001$.

Figure 5: Histopathology of lungs in pigs exposed to chlorine gas. Anesthetized and mechanically ventilated pigs were exposed to either chlorine gas at $\leq 240 \mathrm{ppm}$ or filtered room air for 1 hour. Histopathologic analysis was performed following an official American Thoracic Society (ATS) Workshop Report: Features and Measurements of Experimental Acute Lung Injury in Animals, with some modifications. (Fig 5A) Representative images of the right cranial lobe of lungs are presented. In the air group, normal open alveolar architecture of parenchyma is seen without any significant lesions. In the chlorine group, note partial to complete occlusion of the alveolar air spaces by neutrophils and macrophages, thickening of the alveolar septa by similar inflammatory cells, and edema. Some of the alveolar spaces exhibit protein (either fluid or fibrin). The bar graphs show histopathology scores both in the right cranial lobe and in all lobes.

(Fig 5B) Representative tracheal images are presented. In the air group, normal trachea with pseudostratified columnar epithelium (arrows) and uniform lamina and cartilage (arrowheads) is presented. In the chlorine group, the tracheal mucosa is attenuated with the loss of cilia, and multifocal, abrupt ulcers and marked infiltrates by primarily neutrophils (suppuration) are present (outlined by arrowheads). The surface of the mucosa is overlaid by cell debris, and the 
deeper lamina (arrow) contains infiltrates by lymphocytes, plasma cells, and macrophages.

Tracheal ring cartilage is visible in the air-exposed sections, but not in the chlorine-exposed sections due to edema and inflammation, although all images were taken at the same magnification. The bar graph shows the histopathology score of the trachea. ${ }^{* *}, p \leq 0.01 ; * * * *, p$ $<0.0001$.

All images are presented at 40x magnification.

Figure 6: Chlorinated fatty acids in plasma and lung tissues of chlorine-exposed pigs. Free and total (ie, free + esterified) 2-chlorofatty acids were detected in plasma and lung tissues from both the chlorine and air groups. Free and total fatty acids (2-chloropalmitic acid, 16:0 $\mathrm{Cl}$ and 2chlorostearic acid, 18:0 Cl) were increased in plasma samples that were collected at multiple time points until 24 hours post chlorine exposure (Figure 6A-B). Both free and total 2chloropalmitic acid (Figure 6C) and 2-chlorostearic acid (Figure 6D) were significantly increased in lung tissue samples harvested at 24 hours post chlorine exposure vs filtered room air exposure. *, $p \leq 0.05 ; * *, p \leq 0.01 ; * * *, p \leq 0.001 ; * * * *, p<0.0001$; ns, not significant.

Figure 7: Chlorinated tyrosine adducts in plasma and lung tissues of chlorine-exposed pigs. 3-chlorotyrosine (Cl-Tyr) (Fig 7A ) and 3,5-chlorotyrosine $\left(\mathrm{Cl}_{2}\right.$-Tyr) (Fig 7B) concentrations remained close to lower reportable level (LRL) in plasma samples collected from air-exposed pigs whereas the concentrations have increased significantly in plasma samples collected from chlorine-exposed pigs. In air-exposed animals, the concentrations of $\mathrm{Cl}$-Tyr and $\mathrm{Cl}_{2}$-Tyr were non-detectable whereas were increased by several folds in $\mathrm{Cl}_{2}$-exposed animals (Fig 7C-D). $* \mathrm{p}<0.05$ 


\section{REFERENCES}

1. SCHNEIDER T, LÜTKEFEND T. Nowhere to Hide: The Logic of Chemical Weapons Use in Syria; 2019 February 2019.

2. News U, ITT O. Syrian air force used deadly chemical weapons in 2017 attacks, global watchdog finds. 2020 [cited 2020 05/07/2020]; Available from: https://news.un.org/en/story/2020/04/1061402

3. Ford DA, Honavar J, Albert CJ, Duerr MA, Oh JY, Doran S, Matalon S, Patel RP. Formation of chlorinated lipids post-chlorine gas exposure. J Lipid Res 2016: 57(8): 1529-1540.

4. Hemstrom P, Larsson A, Elfsmark L, Astot C. I-alpha-Phosphatidylglycerol Chlorohydrins as Potential Biomarkers for Chlorine Gas Exposure. Anal Chem 2016.

5. Robaszkiewicz A, Bartosz G, Soszynski M. Detection of 3-chlorinated tyrosine residues in human cells by flow cytometry. J Immunol Methods 2011: 369(1-2): 141-145.

6. Ahmad S, Ahmad A, Hendry-Hofer TB, Loader JE, Claycomb WC, Mozziconacci O, Schoneich C, Reisdorph N, Powell RL, Chandler JD, Day BJ, Veress LA, White CW. Sarcoendoplasmic reticulum Ca(2+) ATPase. A critical target in chlorine inhalation-induced cardiotoxicity. Am J Respir Cell Mol Biol 2015: 52(4): 492-502.

7. Balte PP, Clark KA, Mohr LC, Karmaus WJ, Van Sickle D, Svendsen ER. The Immediate Pulmonary Disease Pattern following Exposure to High Concentrations of Chlorine Gas. Pulm Med 2013: 2013: 325869.

8. Branscomb L, Fagan M, Auerswald PE, Ellis R, Barcham R. Rail Transportation of Toxic Inhalation Hazards: Policy Responses to the Safety and Security Externality. 2010.

9. CDC MaMWR. Public Health Consequences from Hazardous Substances Acutely Released During Rail Transit --- South Carolina, 2005; Selected States, 1999--2004

(https://www.cdc.gov/mmwr/preview/mmwrhtml/mm5403a2.htm). Morbidity and Mortality Weekly Report (MMWR), Centers for Disease Control and Prevention, 2005; pp. 64-67.

10. Mackie E, Svendsen E, Grant S, Michels JE, Richardson WH. Management of chlorine gas-related injuries from the Graniteville, South Carolina, train derailment. Disaster Med Public Health Prep 2014: 8(5): 411-416.

11. Wenck MA, Van Sickle D, Drociuk D, Belflower A, Youngblood C, Whisnant MD, Taylor R, Rudnick $\mathrm{V}$, Gibson JJ. Rapid assessment of exposure to chlorine released from a train derailment and resulting health impact. Public Health Rep 2007: 122(6): 784-792.

12. Branscomb L, Fagan M, Auerswald PE, Ellis R, Barcham R. Rail Transportation of Toxic Inhalation Hazards: Policy Responses to the Safety and Security Externality. Available at SSRN:

https://ssrn.com/abstract=2397482 or http://dx.doi.org/10.2139/ssrn.2397482. 2010: RPP-2010-01

13. Abara W, Wilson S, Vena J, Sanders L, Bevington T, Culley JM, Annang L, Dalemarre L, Svendsen E. Engaging a chemical disaster community: lessons from Graniteville. Int J Environ Res Public Health 2014: 11(6): 5684-5697.

14. Clark KA, Chanda D, Balte P, Karmaus WJ, Cai B, Vena J, Lawson AB, Mohr LC, Gibson JJ, Svendsen ER. Respiratory symptoms and lung function 8-10 months after community exposure to chlorine gas: a public health intervention and cross-sectional analysis. BMC Public Health 2013: 13: 945.

15. Clark KA, Karmaus WJ, Mohr LC, Cai B, Balte P, Gibson JJ, Ownby D, Lawson AB, Vena JE, Svendsen ER. Lung Function before and after a Large Chlorine Gas Release in Graniteville, South Carolina. Ann Am Thorac Soc 2016: 13(3): 356-363.

16. Das R, Blanc PD. Chlorine gas exposure and the lung: a review. Toxicol Ind Health 1993: 9(3): 439-455.

17. Guloglu C, Kara IH, Erten PG. Acute accidental exposure to chlorine gas in the Southeast of Turkey: a study of 106 cases. Environ Res 2002: 88(2): 89-93. 
18. White CW, Martin JG. Chlorine gas inhalation: human clinical evidence of toxicity and experience in animal models. Proc Am Thorac Soc 2010: 7(4): 257-263.

19. Achanta S, Jordt SE. Toxic Effects of Chlorine Gas and Potential Treatments: A Literature Review. Toxicol Mech Methods 2019: 1-34.

20. Van Sickle D, Wenck MA, Belflower A, Drociuk D, Ferdinands J, Holguin F, Svendsen E, Bretous L, Jankelevich S, Gibson JJ, Garbe P, Moolenaar RL. Acute health effects after exposure to chlorine gas released after a train derailment. The American journal of emergency medicine 2009: 27(1):1-7.

21. Winder C. The toxicology of chlorine. Environ Res 2001: 85(2): 105-114.

22. Barrett AM. Mathematical Modeling and Decision Analysis for Terrorism Defense: Assessing Chlorine Truck Attack Consequence and Countermeasure Cost Effectiveness Pittsburgh, Pennsylvania Carnegie Mellon University; 2009.

23. Jani DD, Reed D, Feigley CE, Svendsen ER. Modeling an irritant gas plume for epidemiologic study. Int J Environ Health Res 2016: 26(1): 58-74.

24. GlobalSecurity.org. Chemical Attack - Chlorine Tank Explosion. 2004 [cited 2020 04/08/2020]; Available from: https://www.globalsecurity.org/security/library/report/2004/hsc-planning-scenariosjul04 08.htm

25. Summerhill EM, Hoyle GW, Jordt SE, Jugg BJ, Martin JG, Matalon S, Patterson SE, Prezant DJ, Sciuto AM, Svendsen ER, White CW, Veress LA, Terrorism ATS, Inhalational Disasters Section of the Environmental O, Population Health A. An Official American Thoracic Society Workshop Report: Chemical Inhalational Disasters. Biology of Lung Injury, Development of Novel Therapeutics, and Medical Preparedness. Ann Am Thorac Soc 2017: 14(6): 1060-1072.

26. Achanta S, Jordt SE. Transient receptor potential channels in pulmonary chemical injuries and as countermeasure targets. Ann N Y Acad Sci 2020.

27. 21CFR314.600.

http://www.accessdata.fda.gov/scripts/cdrh/cfdocs/cfcfr/CFRSearch.cfm?CFRPart=314\&showFR=1\&sub partNode=21:5.0.1.1.4.9.

28. Balakrishna S, Song W, Achanta S, Doran SF, Liu B, Kaelberer MM, Yu Z, Sui A, Cheung M, Leishman E, Eidam HS, Ye G, Willette RN, Thorneloe KS, Bradshaw HB, Matalon S, Jordt SE. TRPV4 inhibition counteracts edema and inflammation and improves pulmonary function and oxygen saturation in chemically induced acute lung injury. Am J Physiol Lung Cell Mol Physiol 2014: 307(2): L158172.

29. Judge EP, Hughes JM, Egan JJ, Maguire M, Molloy EL, O'Dea S. Anatomy and bronchoscopy of the porcine lung. A model for translational respiratory medicine. Am J Respir Cell Mol Biol 2014: 51(3): 334-343.

30. Matute-Bello G, Frevert CW, Martin TR. Animal models of acute lung injury. Am J Physiol Lung Cell Mol Physiol 2008: 295(3): L379-399.

31. Matute-Bello G, Downey G, Moore BB, Groshong SD, Matthay MA, Slutsky AS, Kuebler WM, Acute Lung Injury in Animals Study G. An official American Thoracic Society workshop report: features and measurements of experimental acute lung injury in animals. Am J Respir Cell Mol Biol 2011: 44(5): 725-738.

32. Wacker BK, Albert CJ, Ford BA, Ford DA. Strategies for the analysis of chlorinated lipids in biological systems. Free Radic Biol Med 2013: 59: 92-99.

33. Bligh EG, Dyer WJ. A rapid method of total lipid extraction and purification. Can J Biochem Physiol 1959: 37(8): 911-917.

34. Pantazides BG, Crow BS, Quinones-Gonzalez J, Perez JW, Harvilchuck JA, Wallery JJ, Hu TC, Thomas JD, Johnson RC, Blake TA. Development of a clinical assay to measure chlorinated tyrosine in hair and tissue samples using a mouse chlorine inhalation exposure model. Anal Bioanal Chem 2021: 413(6): 1765-1776. 
35. Crow BS, Quinones-Gonzalez J, Pantazides BG, Perez JW, Winkeljohn WR, Garton JW, Thomas JD, Blake TA, Johnson RC. Simultaneous Measurement of 3-Chlorotyrosine and 3,5-Dichlorotyrosine in Whole Blood, Serum and Plasma by Isotope Dilution HPLC-MS-MS. J Anal Toxicol 2016: 40(4): 264-271. 36. Gunnarsson M, Walther SM, Seidal T, Bloom GD, Lennquist S. Exposure to chlorine gas: effects on pulmonary function and morphology in anaesthetised and mechanically ventilated pigs. J Appl Toxicol 1998: 18(4): 249-255.

37. Wang J, Winskog C, Edston E, Walther SM. Inhaled and intravenous corticosteroids both attenuate chlorine gas-induced lung injury in pigs. Acta Anaesthesiol Scand 2005: 49(2): 183-190.

38. Wang J, Abu-Zidan FM, Walther SM. Effects of prone and supine posture on cardiopulmonary function after experimental chlorine gas lung injury. Acta Anaesthesiol Scand 2002: 46(9): 1094-1102.

39. Wang J, Zhang L, Walther SM. Inhaled budesonide in experimental chlorine gas lung injury: influence of time interval between injury and treatment. Intensive Care Med 2002: 28(3): 352-357.

40. Wang J, Zhang L, Walther SM. Administration of aerosolized terbutaline and budesonide reduces chlorine gas-induced acute lung injury. The Journal of trauma 2004: 56(4): 850-862.

41. Wang J, Oldner A, Winskog C, Edston E, Walther SM. Effects of endothelin receptor antagonism on acute lung injury induced by chlorine gas. Critical care medicine 2006: 34(6): 1731-1737.

42. Batchinsky AI, Martini DK, Jordan BS, Dick EJ, Fudge J, Baird CA, Hardin DE, Cancio LC. Acute respiratory distress syndrome secondary to inhalation of chlorine gas in sheep. The Journal of trauma 2006: 60(5): 944-956; discussion 956-947.

43. Watkins R, Perrott R, Bate S, Auton P, Watts S, Stoll A, Rutter S, Jugg B. Development of chlorineinduced lung injury in the anesthetized, spontaneously breathing pig. Toxicol Mech Methods 2021: 31(4): 257-271.

44. Aslan S, Kandis H, Akgun M, Cakir Z, Inandi T, Gorguner M. The effect of nebulized NaHCO3 treatment on "RADS" due to chlorine gas inhalation. Inhalation toxicology 2006: 18(11): 895-900.

45. Artigas A, Bernard GR, Carlet J, Dreyfuss D, Gattinoni L, Hudson L, Lamy M, Marini JJ, Matthay MA, Pinsky MR, Spragg R, Suter PM. The American-European Consensus Conference on ARDS, part 2: Ventilatory, pharmacologic, supportive therapy, study design strategies, and issues related to recovery and remodeling. Acute respiratory distress syndrome. Am J Respir Crit Care Med 1998: 157(4 Pt 1): 13321347.

46. Jackson RM. Molecular, pharmacologic, and clinical aspects of oxygen-induced lung injury. Clin Chest Med 1990: 11(1): 73-86.

47. Esbenshade AM, Newman JH, Lams PM, Jolles H, Brigham KL. Respiratory failure after endotoxin infusion in sheep: lung mechanics and lung fluid balance. J Appl Physiol Respir Environ Exerc Physiol 1982: 53(4): 967-976.

48. Huang SY, Lin JH, Lin EC, Yang PC, Tsou HL. Effects of birth season, breed, sex, and sire family on cardiac morphology determined in pigs (Sus scrofa domestica) by use of echocardiography. Comp Med 2001: 51(6): 545-549.

49. Huang SY, Tsou HL, Chiu YT, Shyu JJ, Wu JJ, Lin JH, Liu SK. Heritability estimate of hypertrophic cardiomyopathy in pigs (Sus scrofa domestica). Lab Anim Sci 1996: 46(3): 310-314.

50. Carlisle M, Lam A, Svendsen ER, Aggarwal S, Matalon S. Chlorine-induced cardiopulmonary injury. Ann N Y Acad Sci 2016: 1374(1): 159-167.

51. Guerin C, Beuret P, Constantin JM, Bellani G, Garcia-Olivares P, Roca O, Meertens JH, Maia PA, Becher T, Peterson J, Larsson A, Gurjar M, Hajjej Z, Kovari F, Assiri AH, Mainas E, Hasan MS, MorochoTutillo DR, Baboi L, Chretien JM, Francois G, Ayzac L, Chen L, Brochard L, Mercat A, investigators of the Apronet Study Group tRNtRrdISFdA-R, the ETG. A prospective international observational prevalence study on prone positioning of ARDS patients: the APRONET (ARDS Prone Position Network) study. Intensive Care Med 2018: 44(1): 22-37. 
52. Munshi L, Del Sorbo L, Adhikari NKJ, Hodgson CL, Wunsch H, Meade MO, Uleryk E, Mancebo J, Pesenti A, Ranieri VM, Fan E. Prone Position for Acute Respiratory Distress Syndrome. A Systematic Review and Meta-Analysis. Ann Am Thorac Soc 2017: 14(Supplement_4): S280-S288.

53. Scholten EL, Beitler JR, Prisk GK, Malhotra A. Treatment of ARDS With Prone Positioning. Chest 2017: 151(1): 215-224.

54. Spickett CM. Chlorinated lipids and fatty acids: an emerging role in pathology. Pharmacol Ther 2007: 115(3): 400-409.

55. Nodelman V, Ultman JS. Longitudinal distribution of chlorine absorption in human airways: a comparison to ozone absorption. Journal of applied physiology 1999: 87(6): 2073-2080. 
Figure 1

\section{A. Study paradigm}

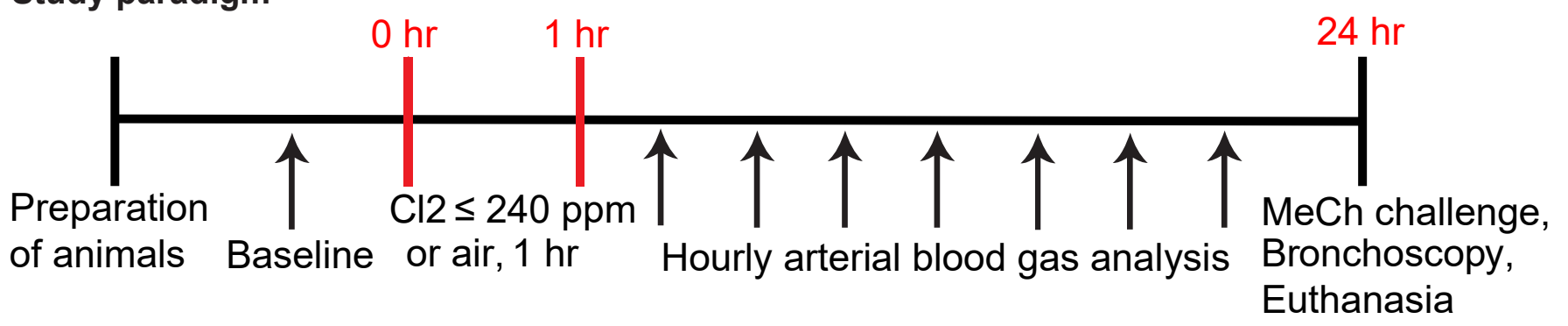

\section{B. Chlorine gas exposure schematic}

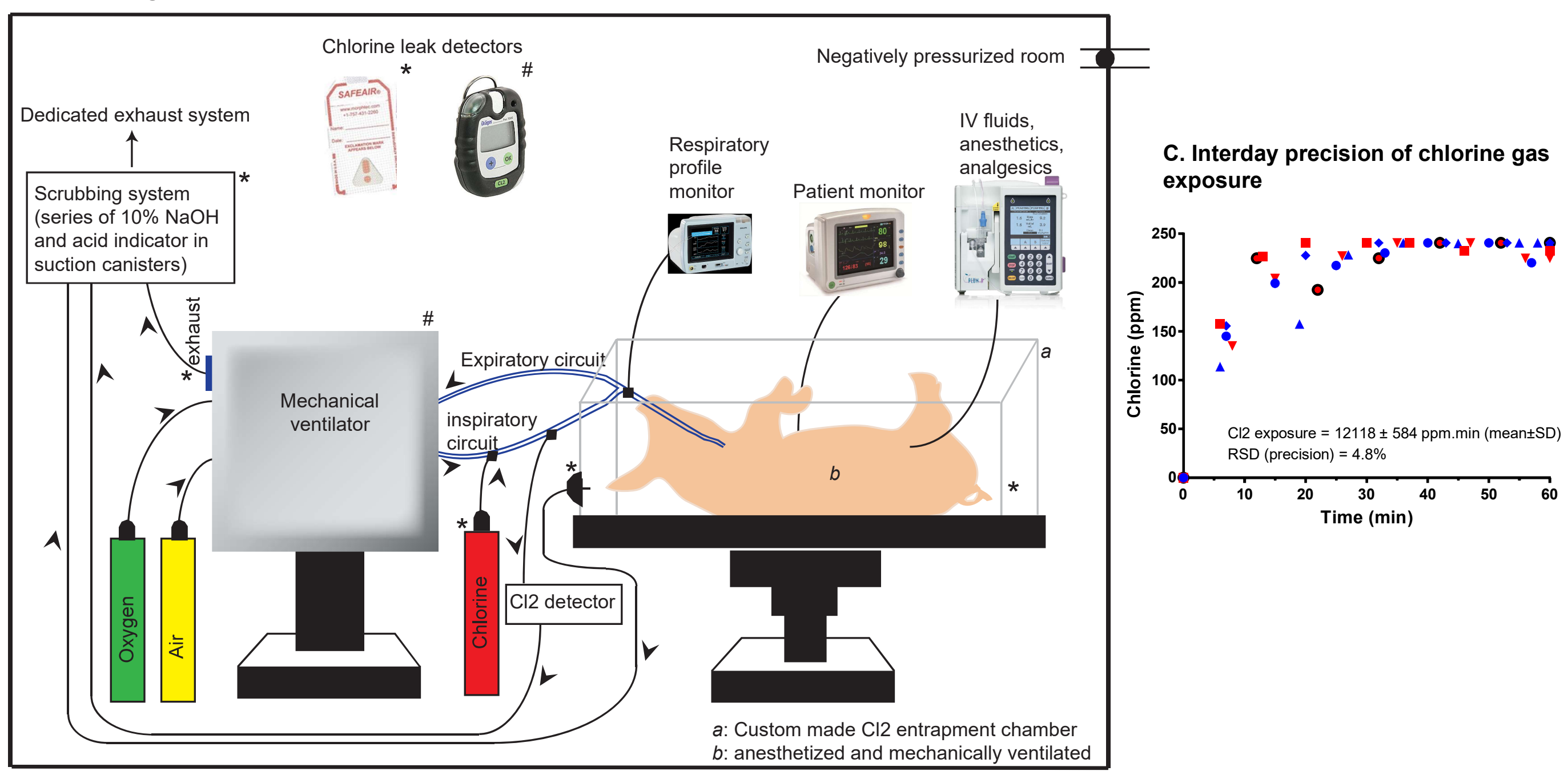


Figure 2

A $\left.\begin{array}{ll} & 0.40 \\ & 0.35 \\ & \\ & 0.30\end{array}\right]$

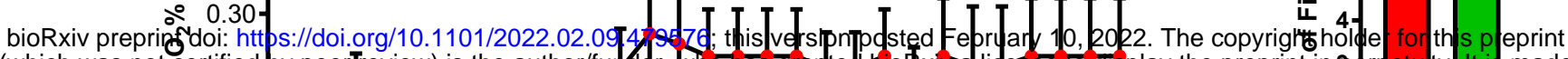

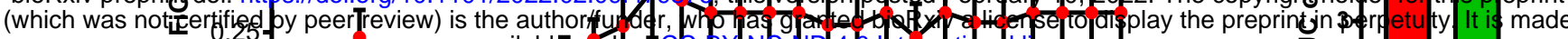

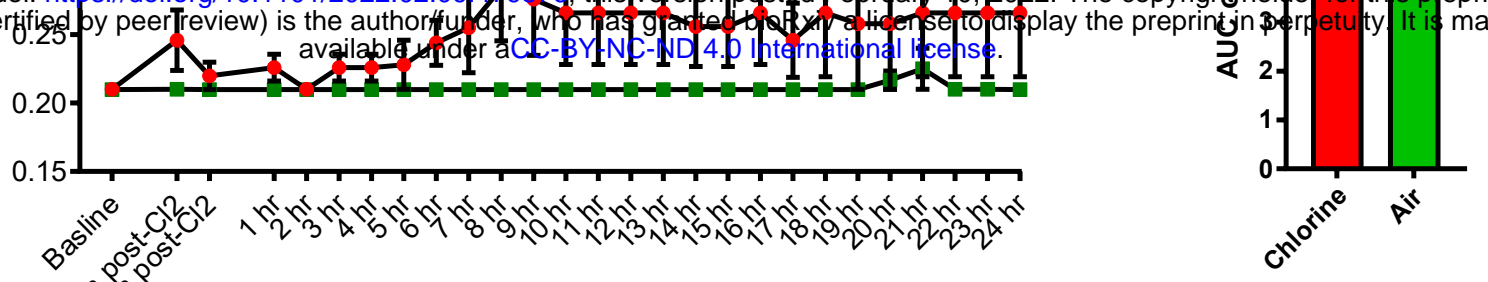

B
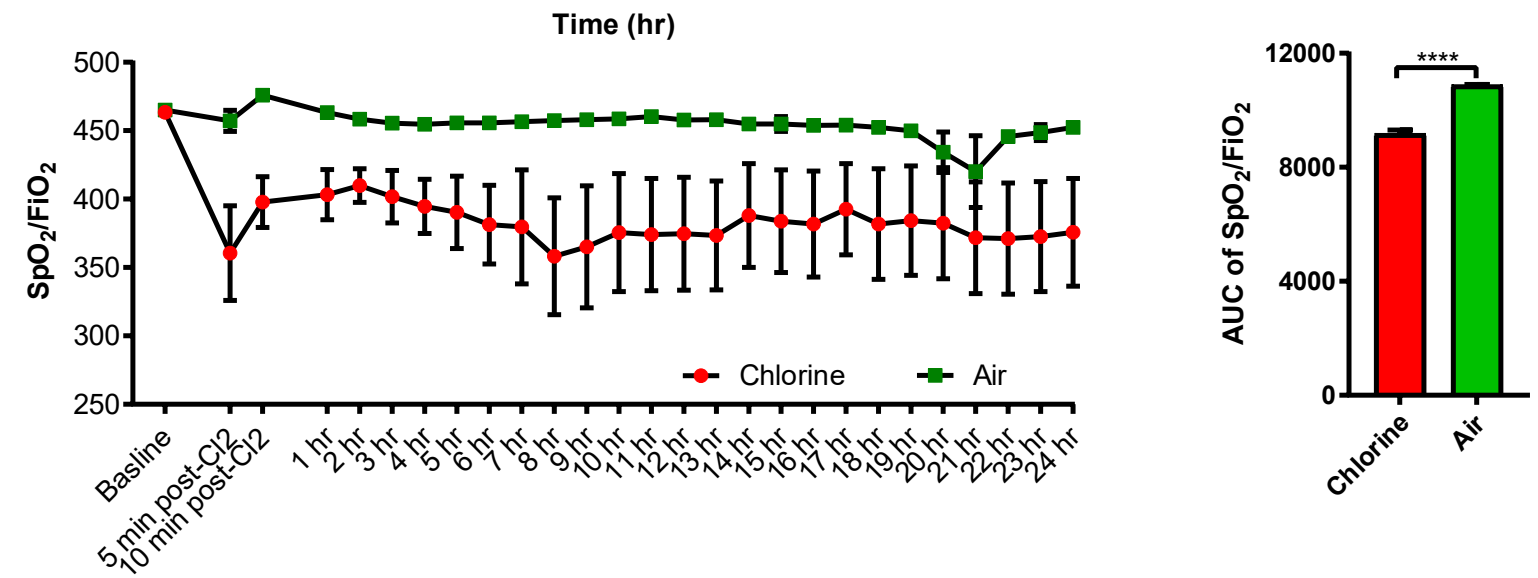

C

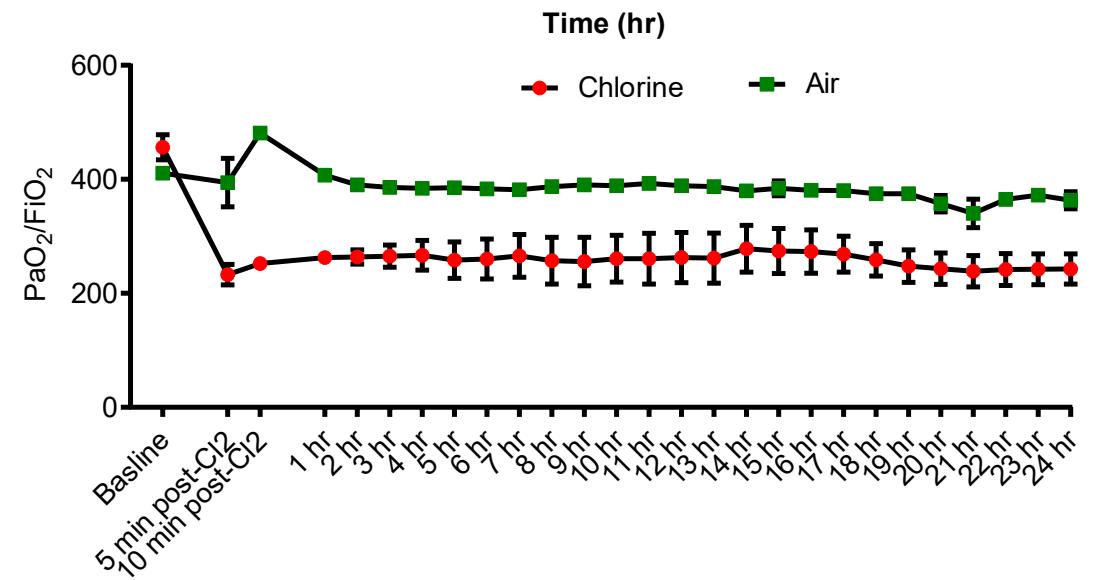

Time (hr)

D
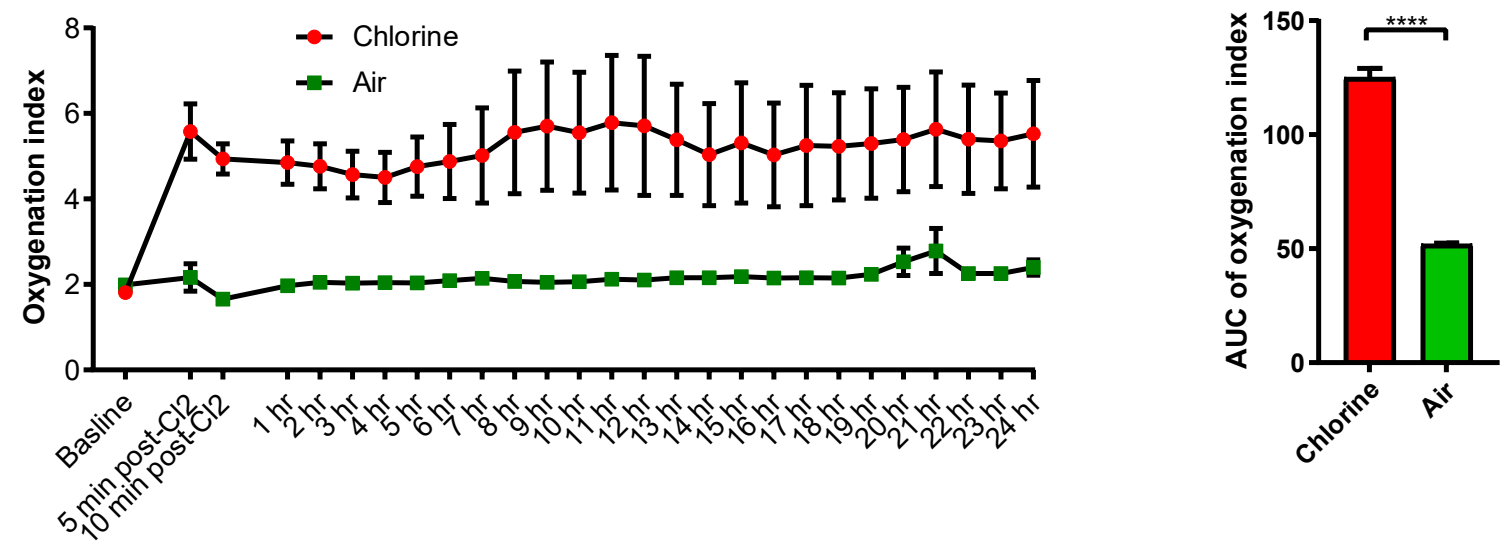

E
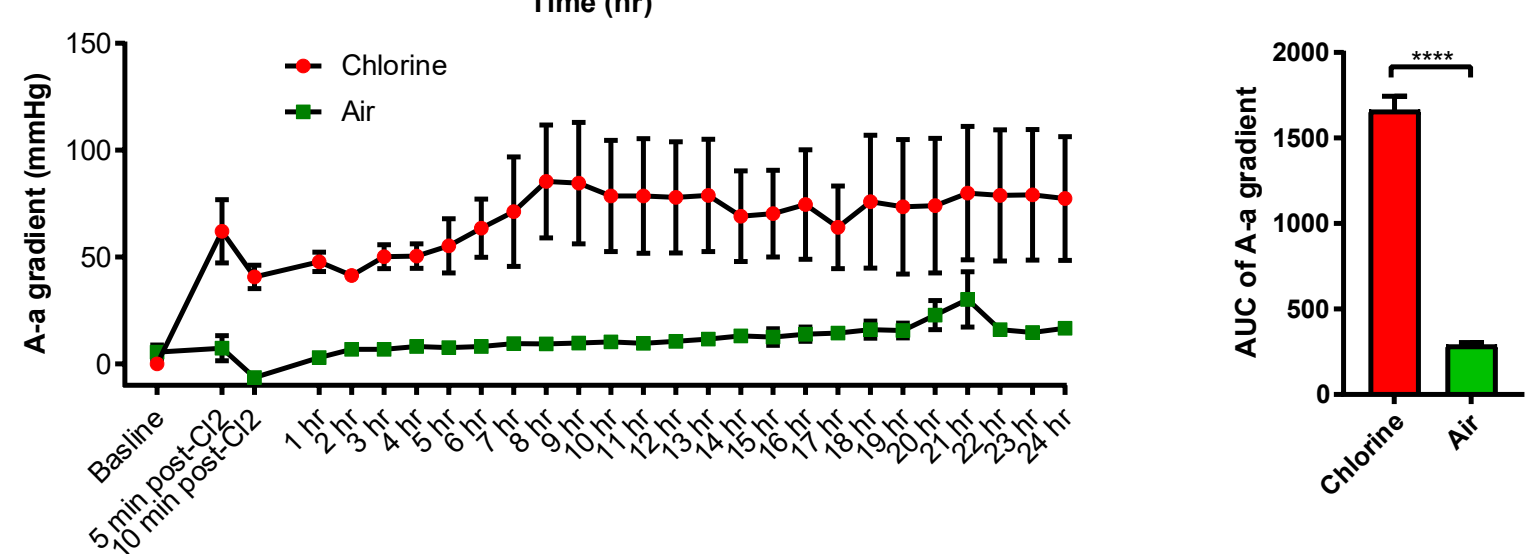
Figure 3

bioRxiv preprint doi: https://doi.org/10.1101/2022.02.09.479576; this version posted February 10, 2022. The copyright holder for this preprint (which was no certified by peer review) is the author/funder, whothas granted bioBxiv a digense to display the preprint in peupe50Q. $7 \mathrm{t}$ is made

A
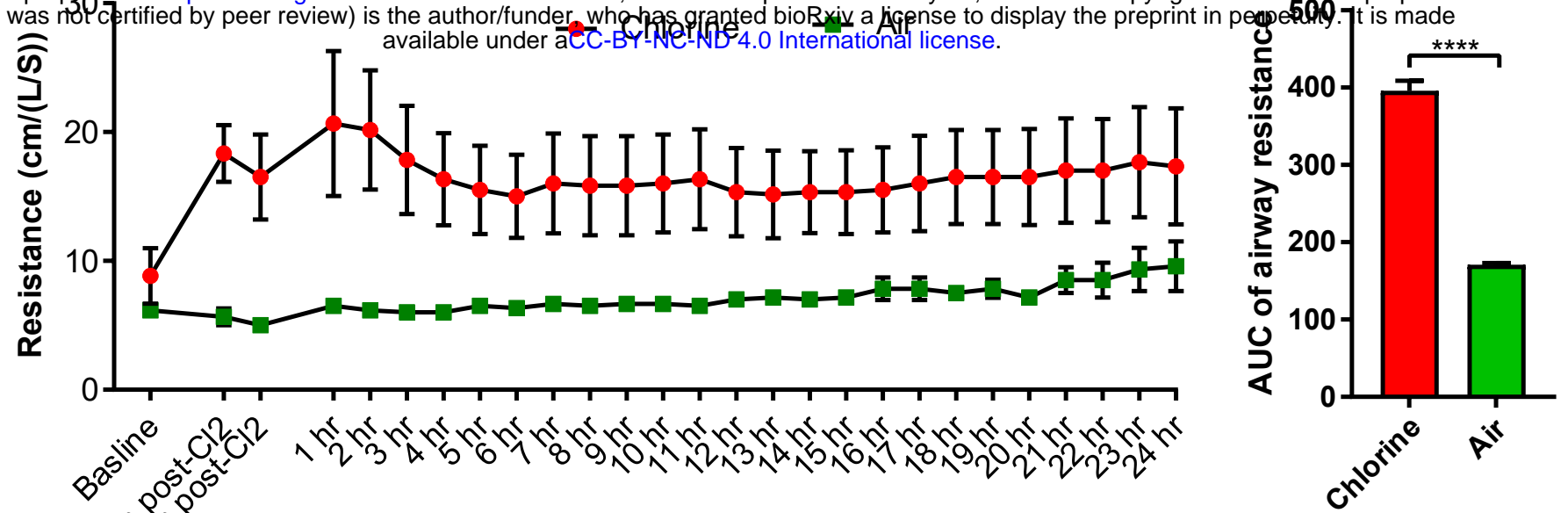

B

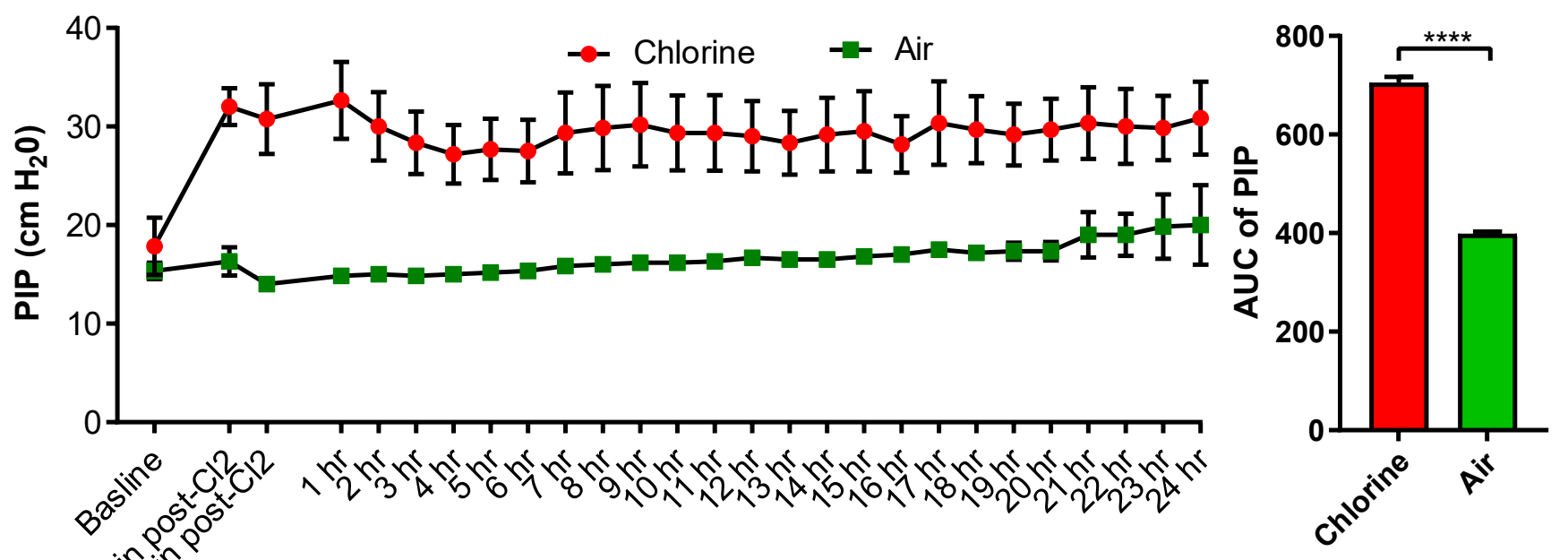

Time (hr)

C
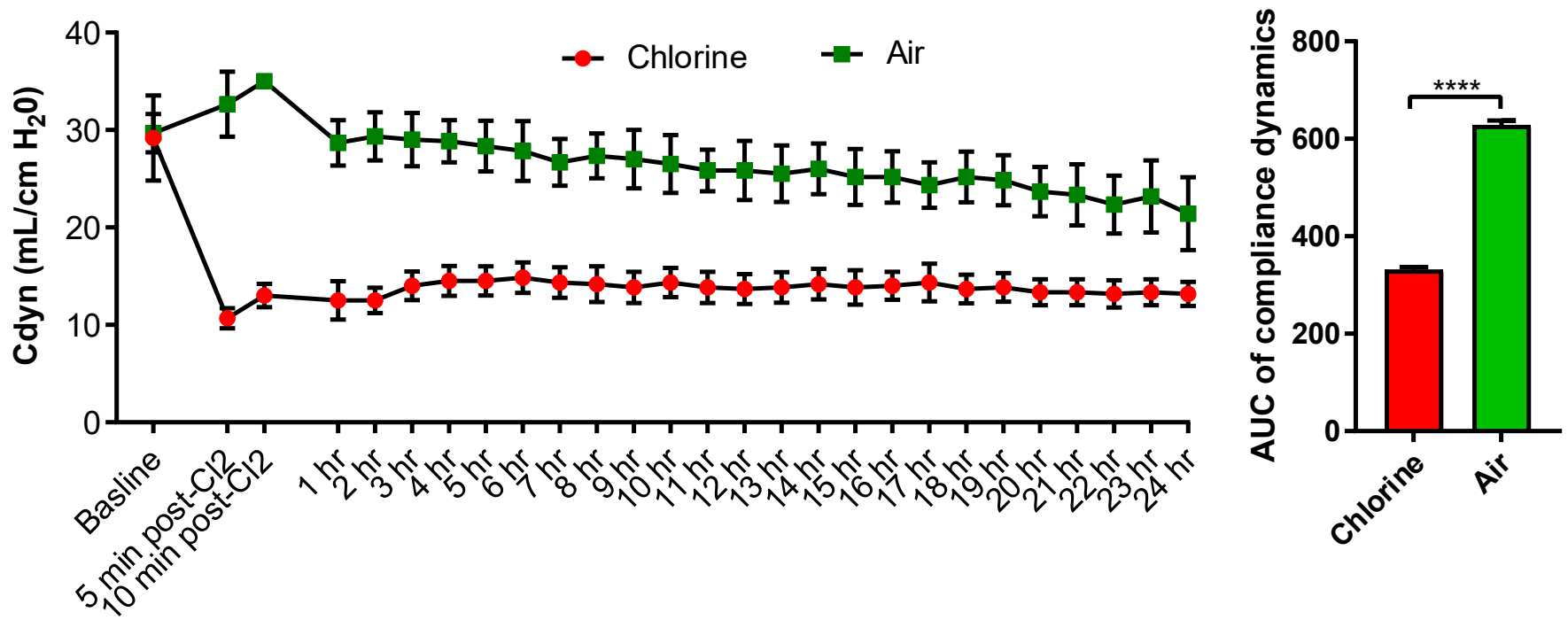
Figure 4

bioRxiv preprint doi: https://doi.org/10.1101/2022.02.09.479576; this version posted February 10, 2022. The copyright holder for this preprint (which was not certified by peer rewe is is the author/funder, who has granted bioRxiv a license to display the preprint in perpetuity. It is made

A

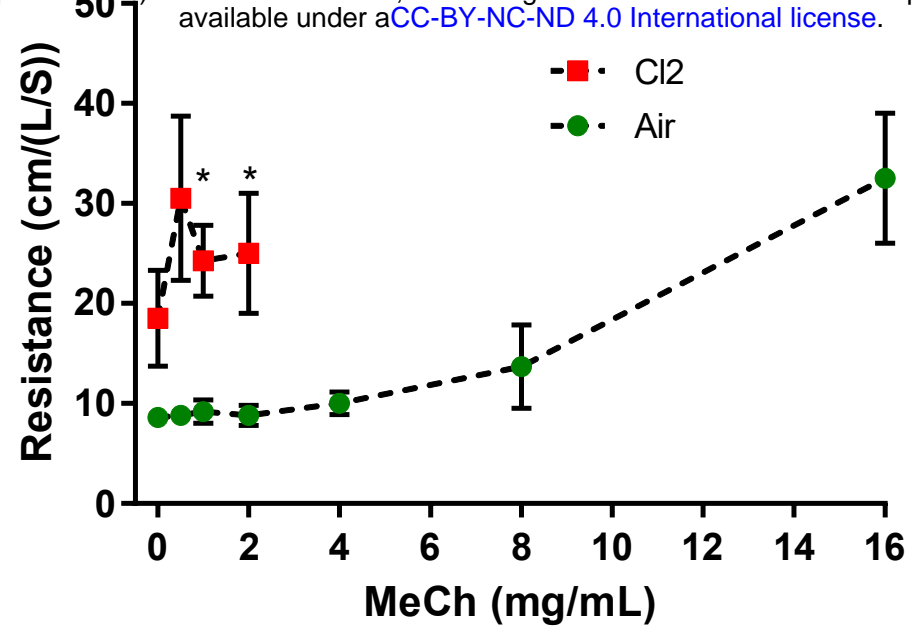

B

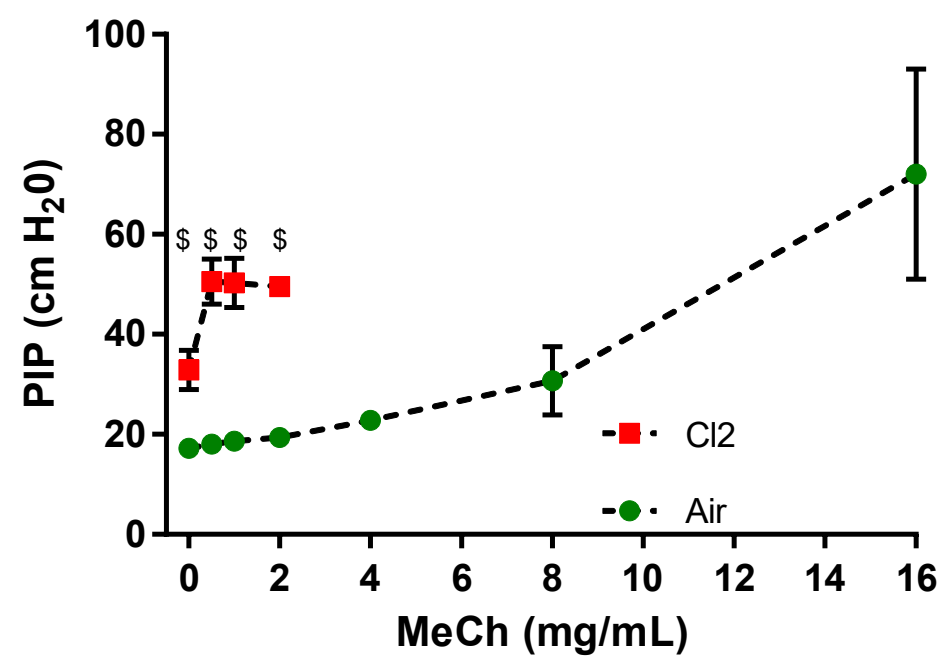

C

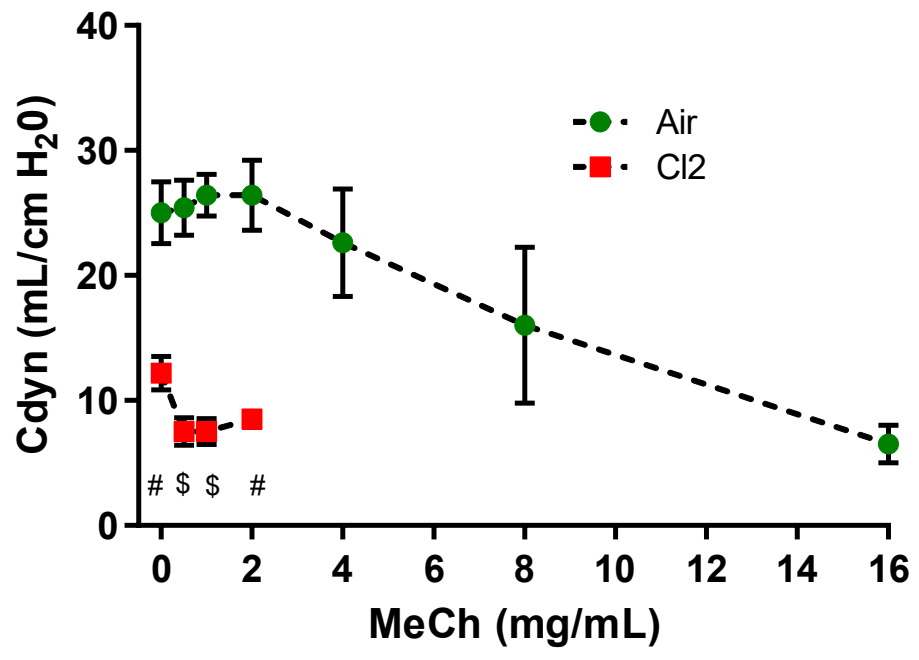


A

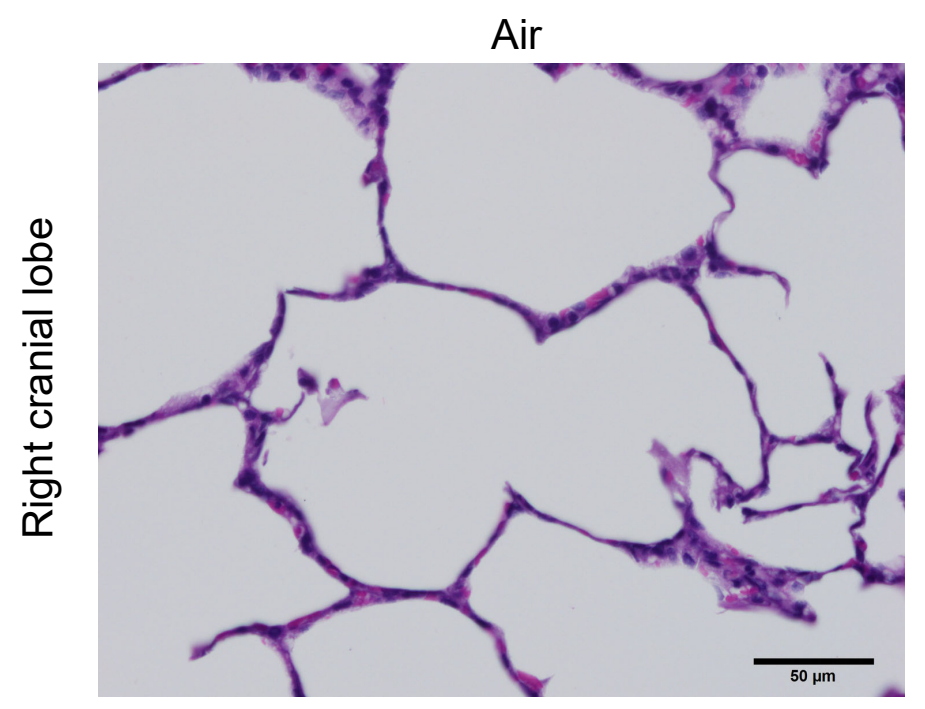

B

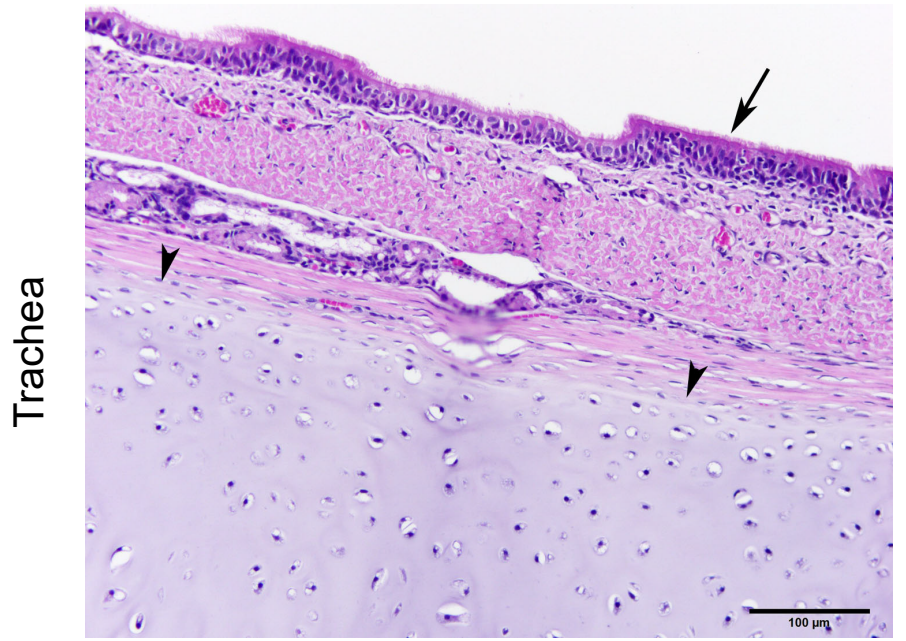

Chlorine

F.0.

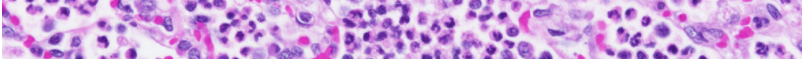

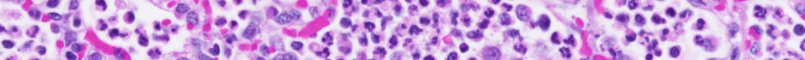

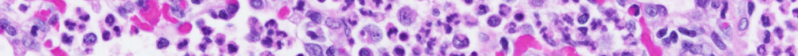

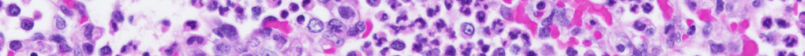

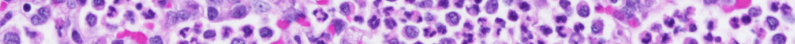

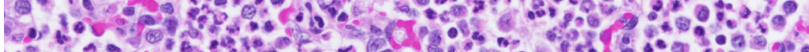

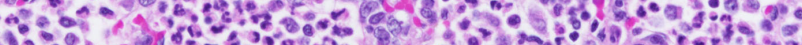
- 3 \%

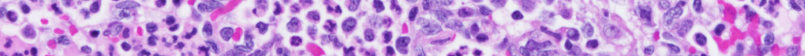

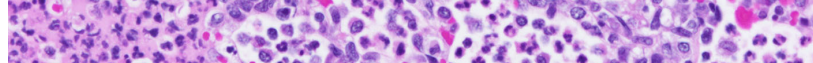

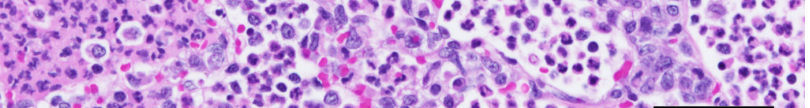

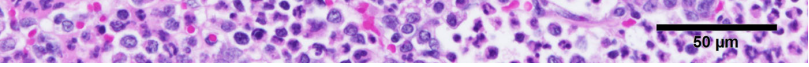

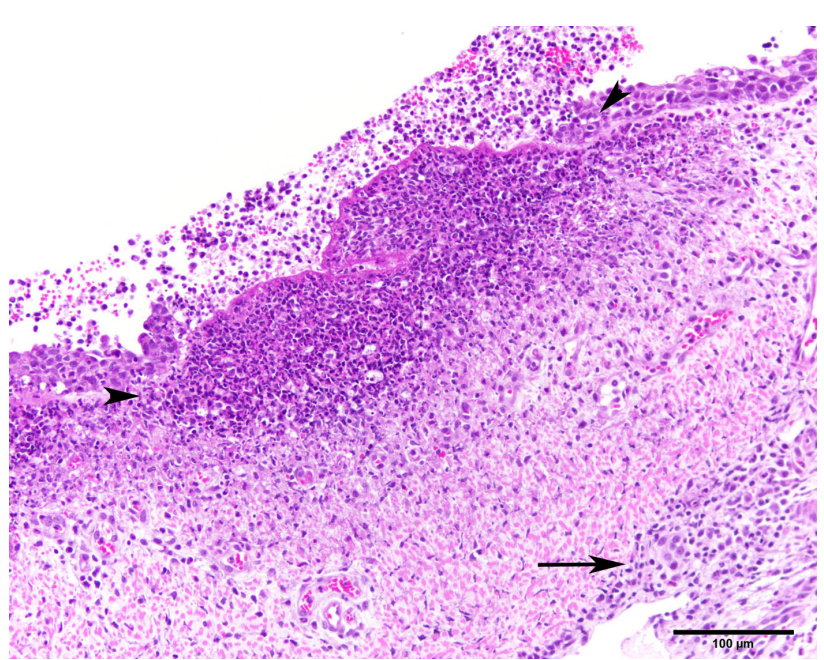

\section{Right cranial lobe}
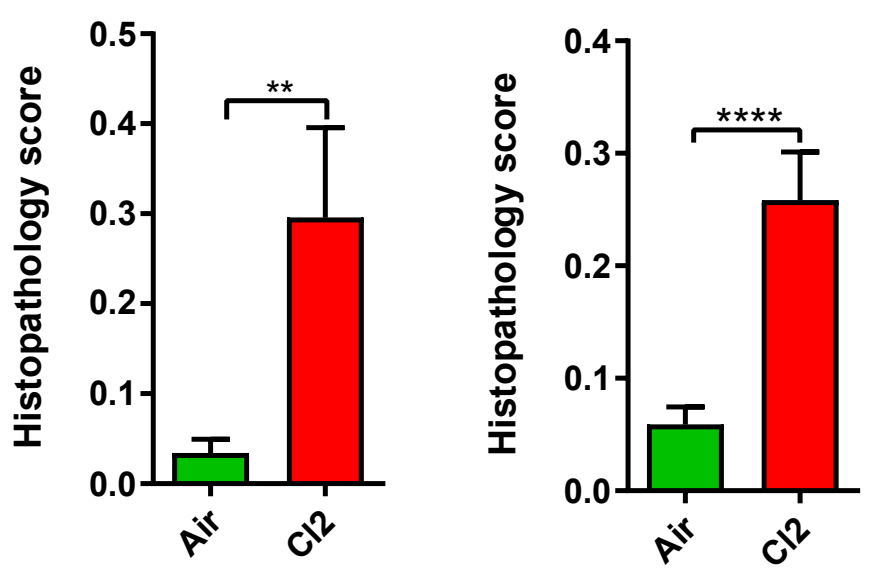

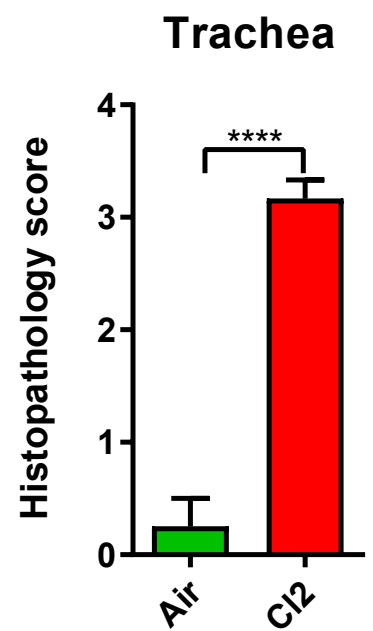




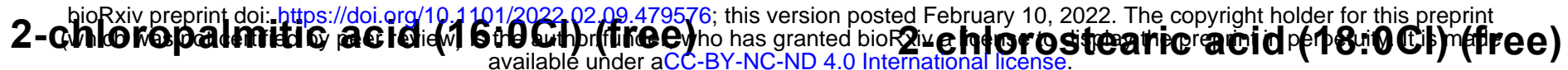
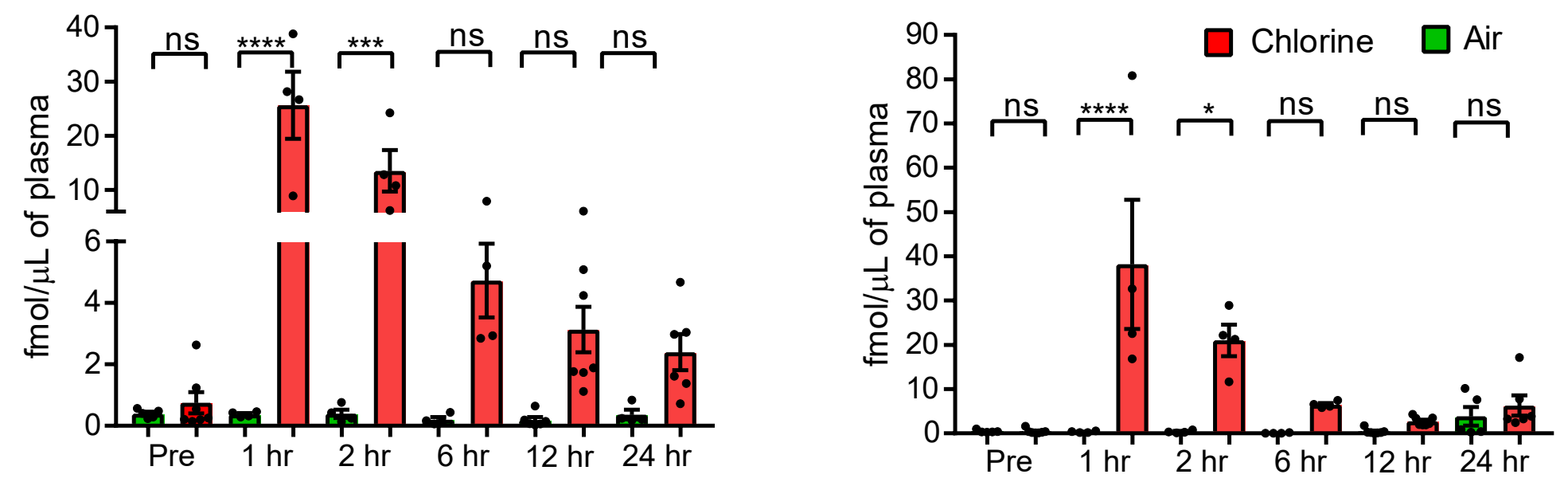

B

2-chloropalmitic acid (16:0Cl) (total)

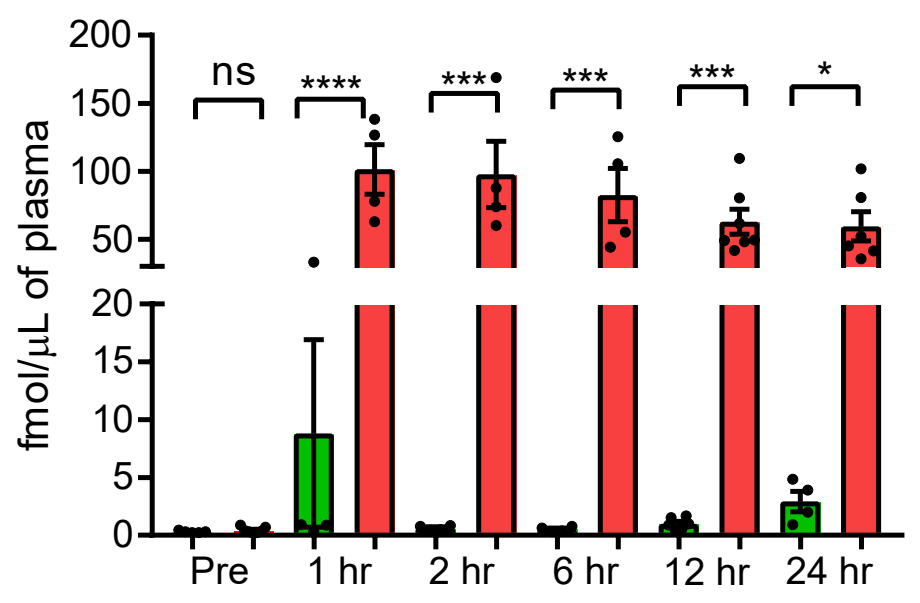

Free 16:0Cl
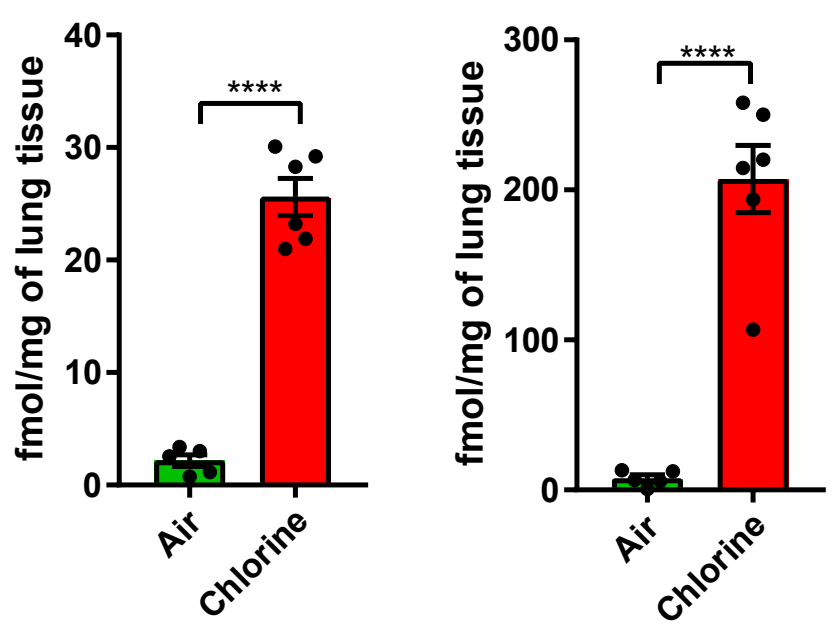

2-chlorostearic acid (18:0Cl) (total)

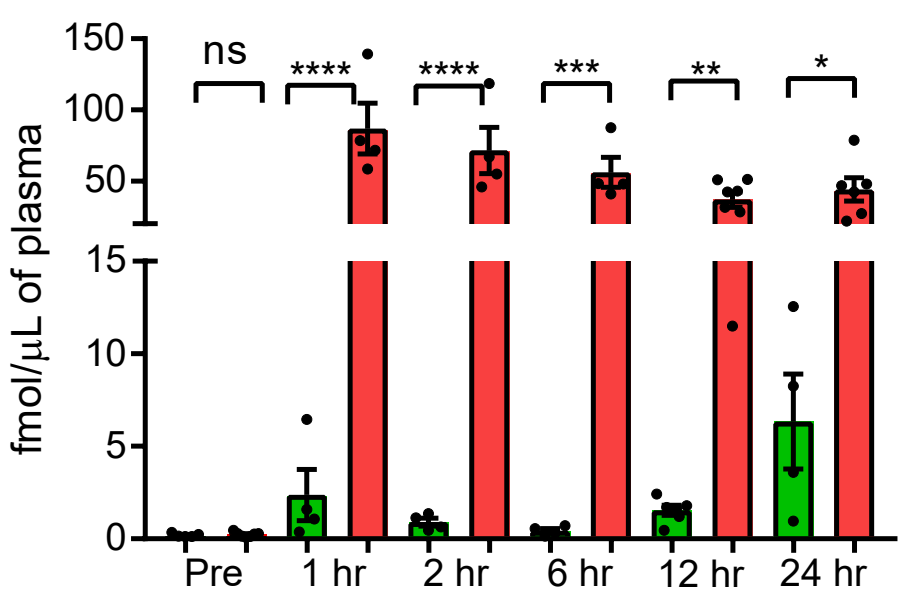

Total $16: 0 \mathrm{Cl}$

Total $18: 0 \mathrm{Cl}$
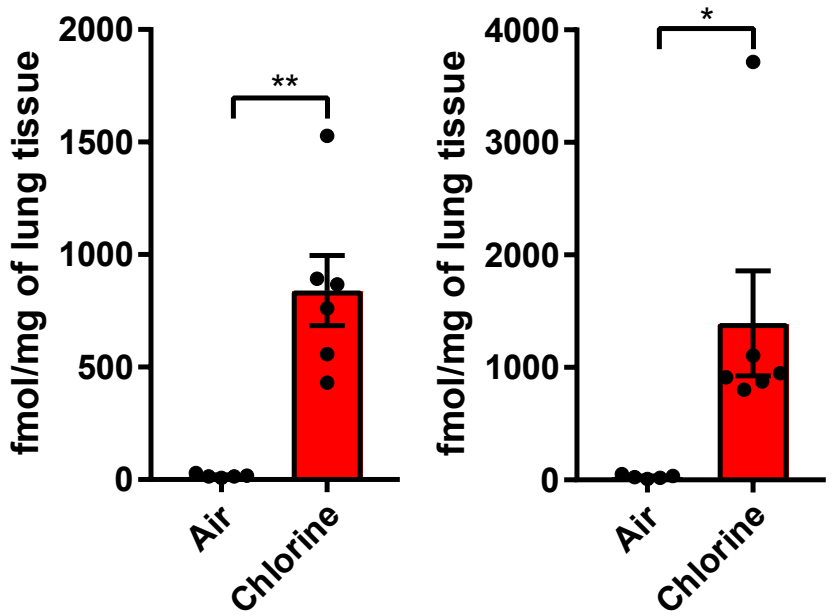
bioRxiv preprint doi: https://doi. org/10.1101/2022 02.09.479576; this version posted February 10,2022 . The copyright holder for this preprint (which was not certified by peer review) is the author/funder, who has granted bioRxiv a license to display the preprint in perpetuity. It is made available under aCC-BY-NC-ND 4.0 International license.

Figure 7

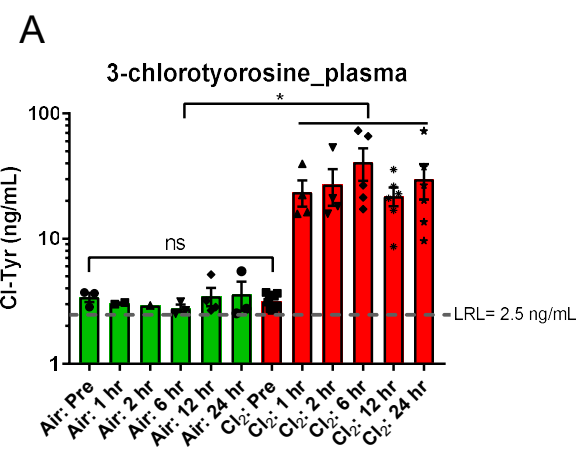

B

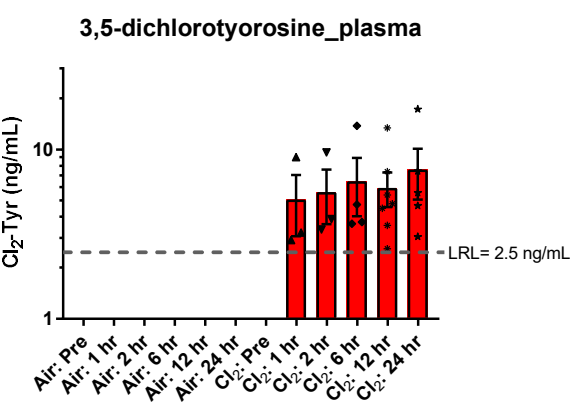

C
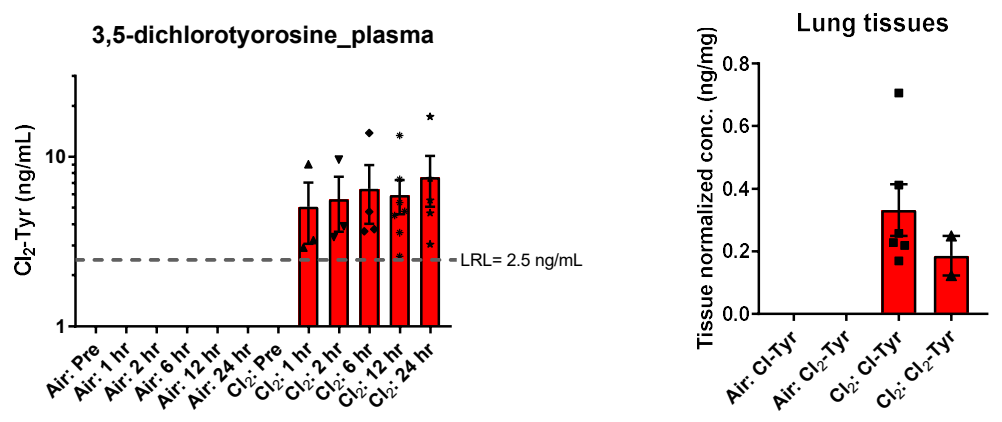